\title{
Land-Use Improvements in the Weather Research and Forecasting Model over Complex Mountainous Terrain and Comparison of Different Grid Sizes
}

\author{
Alessio Golzio ${ }^{1}$ D . Silvia Ferrarese ${ }^{1}$. Claudio Cassardo ${ }^{1}$. \\ Gugliemina Adele Diolaiuti ${ }^{3}$. Manuela Pelfini ${ }^{2}$
}

Received: 30 July 2019 / Accepted: 19 March 2021 / Published online: 28 April 2021

(c) The Author(s) 2021

\begin{abstract}
Weather forecasts over mountainous terrain are challenging due to the complex topography that is necessarily smoothed by actual local-area models. As complex mountainous territories represent $20 \%$ of the Earth's surface, accurate forecasts and the numerical resolution of the interaction between the surface and the atmospheric boundary layer are crucial. We present an assessment of the Weather Research and Forecasting model with two different grid spacings ( $1 \mathrm{~km}$ and $0.5 \mathrm{~km}$ ), using two topography datasets (NASA Shuttle Radar Topography Mission and Global Multi-resolution Terrain Elevation Data 2010, digital elevation models) and four land-cover-description datasets (Corine Land Cover, U.S. Geological Survey landuse, MODIS30 and MODIS15, Moderate Resolution Imaging Spectroradiometer land-use). We investigate the Ortles Cevadale region in the Rhaetian Alps (central Italian Alps), focusing on the upper Forni Glacier proglacial area, where a micrometeorological station operated from 28 August to 11 September 2017. The simulation outputs are compared with observations at this micrometeorological station and four other weather stations distributed around the Forni Glacier with respect to the latent heat, sensible heat and ground heat fluxes, mixinglayer height, soil moisture, 2-m air temperature, and 10-m wind speed. The different model runs make it possible to isolate the contributions of land use, topography, grid spacing, and boundary-layer parametrizations. Among the considered factors, land use proves to have the most significant impact on results.
\end{abstract}

Keywords Boundary layer · Complex mountainous terrain · Glacial foreland · Land cover . Topography

\footnotetext{
Alessio Golzio

alessio.golzio@unito.it

1 Department of Physics, Università degli Studi di Torino, Turin, Italy

2 Department of Earth Sciences “A. Desio”, Università degli Studi di Milano, Milan, Italy

3 Department of Environmental Sciences and Policy, Università degli Studi di Milano, Milan, Italy
} 


\section{Introduction}

The lowest part of the atmosphere - the planetary boundary layer (PBL) and, closer to the land surface, the surface layer - is the region where the exchanges of energy and mass between surface and atmosphere take place (Stull 1988). The interactions between the atmosphere, the cryospheric portion of the hydrosphere, the biosphere, lithosphere, and anthroposphere are especially of interest in high mountain environments, where landscape modifications are increasing under ongoing climatic change (Carlson et al. 2014; Carrivick et al. 2018), and where weather-related hazards and risks are greater (Pelfini et al. 2009; Zanoner et al. 2017). In the Alpine range, glacier shrinkage is accompanied by a progressive widening of glacier forelands (D'Agata et al. 2020), which are available for animal and plant (including trees) colonization. The ongoing deglaciation is leading to increased availability of loose debris susceptible to remobilization by running water and debris flow, with consequences on down-valley territories and on erosion and depositional rates (Bollati et al. 2017; Golzio et al. 2020). Climatic changes mainly drive changes in surface geomorphic processes. However, the landscape-feature modification influences PBL processes, and, consequently, the atmospheric conditions at ground level, as well as the local microclimate, that in turn interact with biological components (e.g., plant germination and growing). Moreover, the high-mountain-environment changes have important implications for human activities such as tourism, mountaineering, sport, and leisure due to both climate-related geomorphic processes and weathering conditions (Pröbstl-Haider et al. 2016). Consequently, exposure to meteorological and geomorphic events can lead to changes in risk scenarios (IPCC 2014). In this fragile environment, accurate forecasts that capture the strength of interactions between the surface and the boundary layer are crucial.

In such complex land topography, even limited-area models have great difficulties in producing a reliable forecast for different reasons: inaccurate input topography, inaccurate input land cover and soil description (LeMone et al. 2006), and also coarse grid spacing. Moreover, in harsh high-mountain environments, direct measurements are rare due to the complexities of installing and maintaining weather stations. One of the widely used localarea models chosen for its versatility is the WRF (Weather Research and Forecasting) model (Skamarock et al.2008), which can be applied to different case studies or used for operational weather forecasting.

In order to better depict the meteorology and atmospheric dynamics in complex terrain, models need high spatial resolution (Balanzino and Trini Castelli 2018). Furthermore, to increase the grid spacing and the consequent effective horizontal resolution (usually from three to six times lower than the grid spacing), some requirements must be fulfilled, such as topographic precision and land-cover description (land use), which must be finer or at least equal to the grid spacing. Concerning topography, there are many different high-resolution digital elevation models (DEMs), but they usually have a national scale and are not consistent between neighbouring nations. However, there is at least one global DEM available from NASA: the Shuttle Radar Topography Mission (SRTM) at 3-arc-second resolution, approximately $90 \mathrm{~m}$ at Alps latitude (NASA-JPL 2013). The land-use description should be sufficiently correct and detailed, and it must be up to date because imprecision in this dataset may impair the model's performance and produce, for example, erroneous surface fluxes (LeMone et al. 2006). For the European continent, the best description of land-use categories is given by the Corine land-cover (CLC) database, last updated in 2012 (Büttner et al. 2014). The database classifies land uses into 44 categories, with a horizontal resolution of $100 \mathrm{~m}$. 
In order to obtain reliable forecasts in complex terrain, it is mandatory to run meteorological models at very high horizontal grid resolution, typically on a sub-km scale. Such scales lie in the terra incognita (Wyngaard 2004) because here the turbulent eddies in the PBL are partially resolved and partially parametrized. Furthermore, many atmospheric processes may change in scale as they develop and can enter or leave the grey zone (Kealy et al. 2019). Therefore, PBL parametrizations can only partially describe these processes, but the selection of the PBL parametrization is indeed crucial.

Here, we investigate if the use of detailed land-use and topography data improves model performance using a set of standard parametrizations. Many studies have previously evaluated the parametrizations of the WRF model, with a particular focus on PBL parametrizations. They compare different closure-order parametrizations, local and non-local, or with a particular interest on some specific state or phenomena of the PBL, such as stability or entrainment (e.g., Balzarini et al. 2014; Cohen et al. 2015; Goger et al. 2016; Sun et al. 2017; Ferrero et al. 2018; Tyagi et al. 2018; Roşu et al. 2019). Here, two PBL parametrizations are applied in the high-resolution simulations. However, our purpose is to understand to what extent the static data and the horizontal grid spacing improve the representation of the atmospheric conditions in a mountainous environment characterized by complex terrain and the presence of a glacier body using a fixed set of parametrizations.

In particular, we propose a new land-use table that considers all 44 classes of the CLC database. A couple of previous evaluations of the WRF model with high-resolution static data include De Meij and Vinuesa (2014) with 1-km resolution in northern Italy, and Jiménez-Esteve et al. (2018) in the Pyrenees with a resolution up to $0.5 \mathrm{~km}$ using a downscaling approach to the innermost domain but without real-time two-way nesting. More significant improvements were made by Gerber et al. (2018), who initialized the WRF model with COSMO-2 (COnsortium for Small-scale MOdelling) boundary conditions and ran it with 50-m horizontal resolution in large-eddy-simulation mode. It is worth noting the results of Sun et al. (2017), who applied the WRF model at $0.5-\mathrm{km}$ resolution over farmland in the U.S.A. Even if they used different land use (MODIS, Moderate Resolution Imaging Spectroradiometer, and USGS, U.S. Geological Survey) and compared several PBL parametrizations, they concluded that there was no best configuration for both surface heat fluxes and meteorological variables.

Here, the WRF model was run with seven different set-ups with different land-use and topographic datasets, horizontal grid spacing, and PBL parametrizations. We hypothesized that: (1) a more detailed land-use dataset improves the performances of the WRF model; (2) a more detailed topography improves the performances of the WRF model, especially in complex terrain; and (3) a smaller grid spacing (e.g., from $1 \mathrm{~km}$ to $0.5 \mathrm{~km}$ ) improves the performances of the WRF model in mountainous terrain. Moreover, we wish to investigate (4) to what degree a non-local PBL parametrization affects the model performance in terms of the PBL variables.

To disentangle these hypotheses the work is organized into the following points:

1. the WRF mesoscale model was tested in a rather complex area centred on the Rhaetian Alps (Central Italian Alps) and in particular on the Ortles-Cevedale Group and Forni Glacier;

2. seven different set-ups were used to assess whether and how the improvements of the land-use dataset, DEM, grid spacing and PBL parametrization enhance the forecast skills of the WRF model for (a) temperature, (b) low-level wind speed and direction and (c) sensible heat flux; 
3. the verification compares model results with observations from weather stations and one micrometeorological station;

4. the simulations were compared using a Student's $t$-test for the outputs of sensible, latent and ground heat fluxes, soil moisture, 10-m wind speed, and 2-m air temperature.

\section{Observations, Model, and Methodology}

\subsection{The Experiment}

The experimental study area is located in the upper part of the Forni Valley, a typical Alpine glacial valley, which extends into Valfurva, a tributary of the central Valtellina valley. Forni Valley is inside the Stelvio National Park and belongs to the Lombardy sector of the Ortles Cevedale Massif in the Central Italian Alps.

The experimental campaign data against which the WRF model was tested started on 28 August 2017 and ended on 11 September 2017. During this campaign, a micrometeorological station was installed at the Forni Glacier foreland.

The valley topography is complex, as with other higher alpine territories; the landscape has been deeply shaped by glaciers and, following the deglaciation, by mass wasting, mass movements, and running waters (Pelfini et al. 2014; Masseroli et al. 2016). The valley is surrounded by many peaks higher than $3000 \mathrm{~m}$ above sea level (a.s.l.), and the valley bottom ranges from $1800 \mathrm{~m}$ a.s.l. at the beginning in Santa Caterina Valfurva to $2500 \mathrm{~m}$ a.s.l. at the Forni Glacier foreland. The landscape is dominated by the Forni Glacier, the second-largest glacier in extent of the Italian Alps (Smiraglia et al. 2016). The study area is depicted in Fig. 1.

Forni Glacier is going through a high-shrinkage phase under the present climatic trend. It has been studied for a long time, and recently scientific attention has focused on the glacier dynamics, its responses to climate change (e.g., Senese et al. 2018; Golzio et al. 2018), the implications with regard to the biological systems (Gobbi et al. 2006; Franzetti et al. 2020) and different cultural, historical, and heritage components (Pelfini and Gobbi 2005; Francese et al. 2015) and human utilization (Garavaglia et al. 2012).

During the experimental campaign conducted at the Forni Glacier foreland, an automatic weather station called MiTo was installed. It was equipped with standard meteorological instruments (thermometer, wind vane, and cup anemometer) and with high-frequency instruments to measure turbulence (an ultrasonic anemometer and a krypton hygrometer). The description of the instrumentation is given in Table 1 and a comprehensive picture of the station is shown in Fig. 2.

The weather situation, derived from measurements made at the MiTo station and through the analysis of weather charts, presented a first period of fair and typical end-of-summer weather (from 28 to 30 August). Some scattered clouds were present, especially in the afternoon, and a local thunderstorm was recorded during the afternoon of 28 August. A front crossed the Alps on 31 August and brought cold air and precipitation in the form of snow above $2300 \mathrm{~m}$ a.s.l. The frontal system also generated a small lee-side cyclone over the Ligurian Sea, and the connected warm front also affected the Central Italian Alps in the subsequent week. The cloudy and rainy, or snowy, weather ended on 4 September, when a weak ridge formed over southern Europe. A second rapid cold front crossed the Alps between 8 and 10 September, and brought precipitation to the Forni Glacier foreland. 


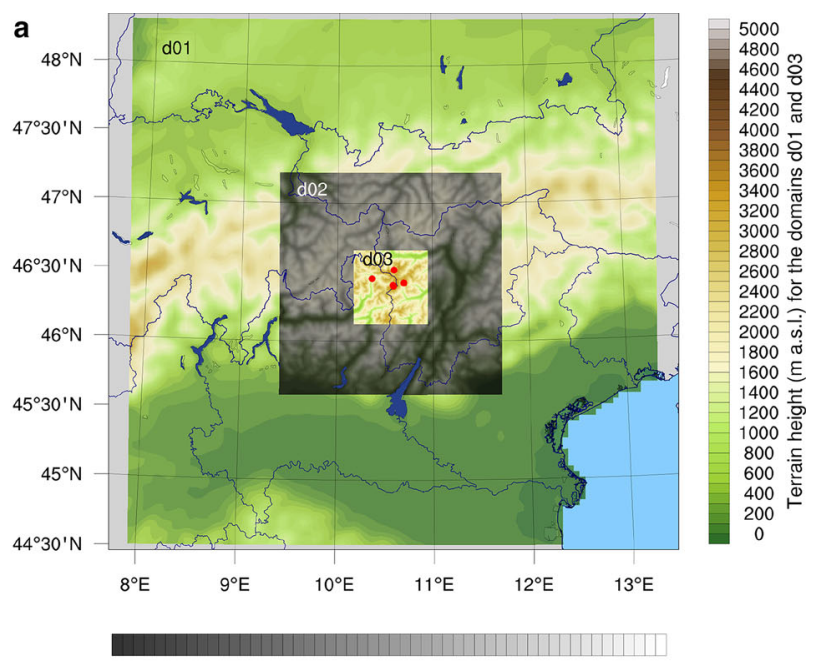

$0 \quad 500 \quad 1000150020002500 \quad 3000 \quad 3500 \quad 4000 \quad 4500 \quad 5000$

Terrain height ( $m$ a.s.l.) for the domain d02

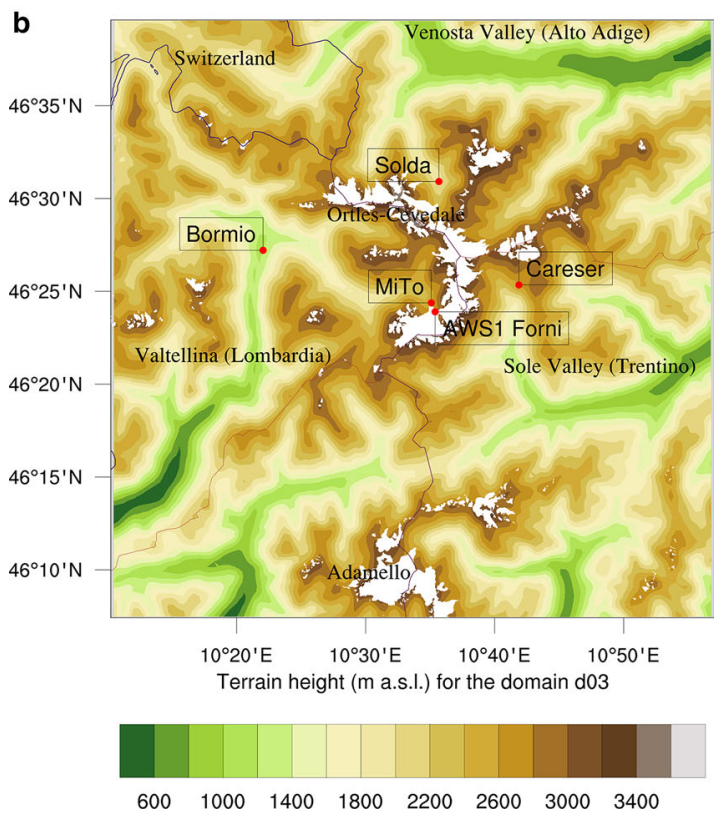

Fig. 1 The WRF model domains with topography. a The three domains centred on the Forni Glacier foreland; the topography of the parent domain (d01) and the middle domain (d02) is the GMTED2010 data at 30arc-second resolution, whereas the inner domain (d03) uses NASA SRTM data at 3-arc-second. b The inner domain (d03) is shown for the background topography given by NASA SRTM data at 3-arc-second resolution; red dots indicate the positions of weather stations used for the comparison, and the white areas represent the glacier extent in 2018 (Raup et al. 2007; GLIMS and NSIDC 2018) 
Table 1 Details of the MiTo station at the Forni Glacier foreland

\begin{tabular}{llll}
\hline Instrument & Make and model & Height $(\mathrm{m})$ & Direction relative to north \\
\hline Ultrasonic anemometer & $\begin{array}{l}\text { Solent R2-research, Gill, } \\
\text { Poole, U.K. }\end{array}$ & $2.59 \pm 0.01$ & $5^{\circ} \pm 2^{\circ}$ \\
KH20, CampbellSci, & $2.76 \pm 0.01$ & \\
Hygrometer & $\begin{array}{l}\text { Shepshed, U.K. } \\
\text { SVDV, Siap+Micros, } \\
\text { Anemometer and }\end{array}$ & $2.04 \pm 0.01$ & $0^{\circ} \pm 2^{\circ}$ \\
$\begin{array}{l}\text { Sind vane } \\
\text { Thermometer }\end{array}$ & $\begin{array}{l}\text { San Fior, Italy } \\
\text { Thermocouple type K }\end{array}$ & $1.81 \pm 0.01$ & \\
&
\end{tabular}

Fig. 2 The weather station MiTo installed at the Forni Glacier forelands, which collected data between 28 August and 11

September 2017; it was equipped with an ultrasonic anemometer at the top of the mast, a fast hygrometer (beside the ultrasonic anemometer), and two traditional meteorological instruments: a wind vane with a cup anemometer, and a thermometer

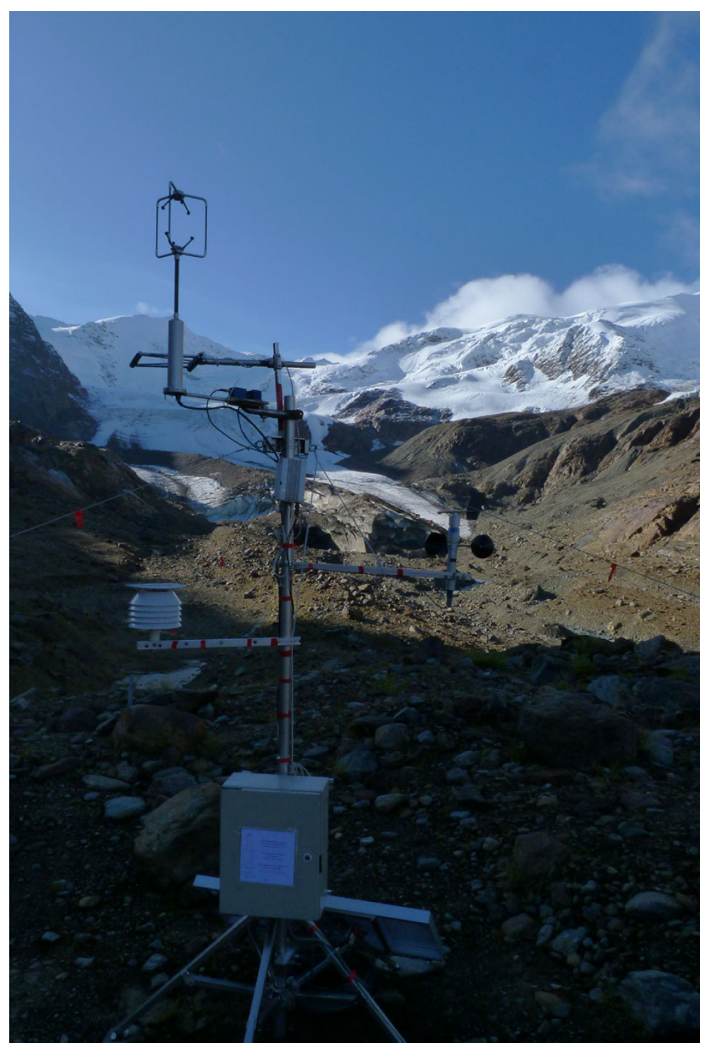

\subsection{Meteorological Measurements}

Besides the MiTo station, four other weather stations are considered, and were located all around the Forni Glacier foreland in order to completely describe the local weather on the different sides of the Ortles Cevedale group. The stations chosen were: Bormio CNSAS (Corpo Nazionale Soccorso Alpino e Speleologico) in Valtellina, Forni Glacier station (on the glacier), Solda in Venosta Valley, and Careser dam in Sole Valley (Table 2 and Fig. 1b). The complete set of stations was used to assess the WRF model performance in several complex-terrain areas; hence, there were two valley-bottom stations (Bormio and Solda), a 
Table 2 Meteorological stations used for model performance estimation

\begin{tabular}{llllll}
\hline Station name & Lat N, Long E & Altitude (m) & Parameters & Net & Type \\
\hline AWS1 Forni & $46.399,10.590$ & 2700 & P, T, RH, R & 1 & Glacier \\
MiTo & $46.407,10.585$ & 2522 & T, WS, WD, Turb & 1,2 & Glacier foreland \\
Bormio & $46.454,10.366$ & 1172 & P, T, RH, WS, WD & 3 & Valley floor \\
Solda & $46.516,10.595$ & 1907 & P, T, RH, R & 4 & Valley floor \\
Careser & $46.423,10.699$ & 2600 & P, T, RH, WS, WD & 5 & High-altitude lake
\end{tabular}

Stations coordinates are expressed in degrees north or east. The altitude is expressed in $\mathrm{m}$ a.s.l. Available parameters are abbreviated as follows: $\mathrm{P}$ - precipitation, T-2-m temperature, WS — wind speed, WD-wind direction, RH-relative humidity, R-solar radiation, Turb - turbulence parameters from sonic anemometer. Networks (Net) are abbreviated as follows: 1-University of Milan Department of Environmental Sciencies and Policy, 2-University of Turin Department of Physics, 3-Environmental Protection Agency of Lombardy region, 4-Bolzano province weather service, 5-Meteotrentino

glacier station (AWS1 Forni), a high-altitude station near a lake (Careser), and the newly installed glacier foreland turbulence station (MiTo).

\subsection{Weather Research and Forecasting Model Configuration for the Case Study}

Here, the Advanced Research WRF model version 3.9.1 (April 2017) was used with three nested domains (parent d01, middle d02, with inner d03, Fig. 1), and the main characteristics of each domain summarized in Table 3. Initial and boundary conditions have been provided by the ECMWF (European Centre for Medium-Range Weather Forecasts) ERA5 reanalysis archive. The parametrizations were chosen following several studies applying the WRF model at high resolution in complex terrain (e.g., De Meij and Vinuesa 2014; Gerber et al. 2018), as well as suggestions contained in the WRF model user page. In particular, the microphysics WRF single-moment 6-class scheme (Hong and Lim 2006) was chosen as appropriate for the selected horizontal resolution, and two PBL parametrizations were applied. The first is the one-dimensional Mellor-Yamada-Janjic (MYJ, Janjic 1994) parametrization, which uses a local diffusion parametrization, and is considered as the reference case. The second is the non-local Yonsei University diffusion parametrization (YSU, Hong et al. 2006), which could be beneficial in the convective boundary layer. The YSU parametrization has been shown to give the best performance over complex terrain by Gómez-Navarro et al. (2015), and is here activated with the orographic drag option (Jiménez and Dudhia 2012). The choice to use the YSU parametrization was due to the availability of subgrid orography wind drag for enhancement of the flow prediction performances and the non-local characteristic. The surface-layer parametrization is directly connected with the PBL parametrization: the MYJ parametrization requires the Eta-Similarity parametrization (Janjic 2002), while the YSU parametrization requires the Revised MM5 parametrization (Jiménez et al. 2012). Land surface was parametrized by applying the Unified Noah Land Surface model while short- and longwave radiation were computed using the New Goddard and RRTM (Rapid Radiative Transfer Model) parametrizations, respectively (Table 3).

The central point (reference latitude and longitude) of the parent domain (d01) is located at $46.44^{\circ} \mathrm{N}$ and $10.59^{\circ} \mathrm{E}$, and the map projection used is Lambert Conformal. The nested domains are placed with the same central point. The model set-up includes 44 vertical eta levels, up to the 100 -hPa pressure level $(\approx 17,000 \mathrm{~m}$ a.s.l., in the stratosphere), and were calculated following the Giovannini et al. (2014) eta-levels distribution. The first level is 


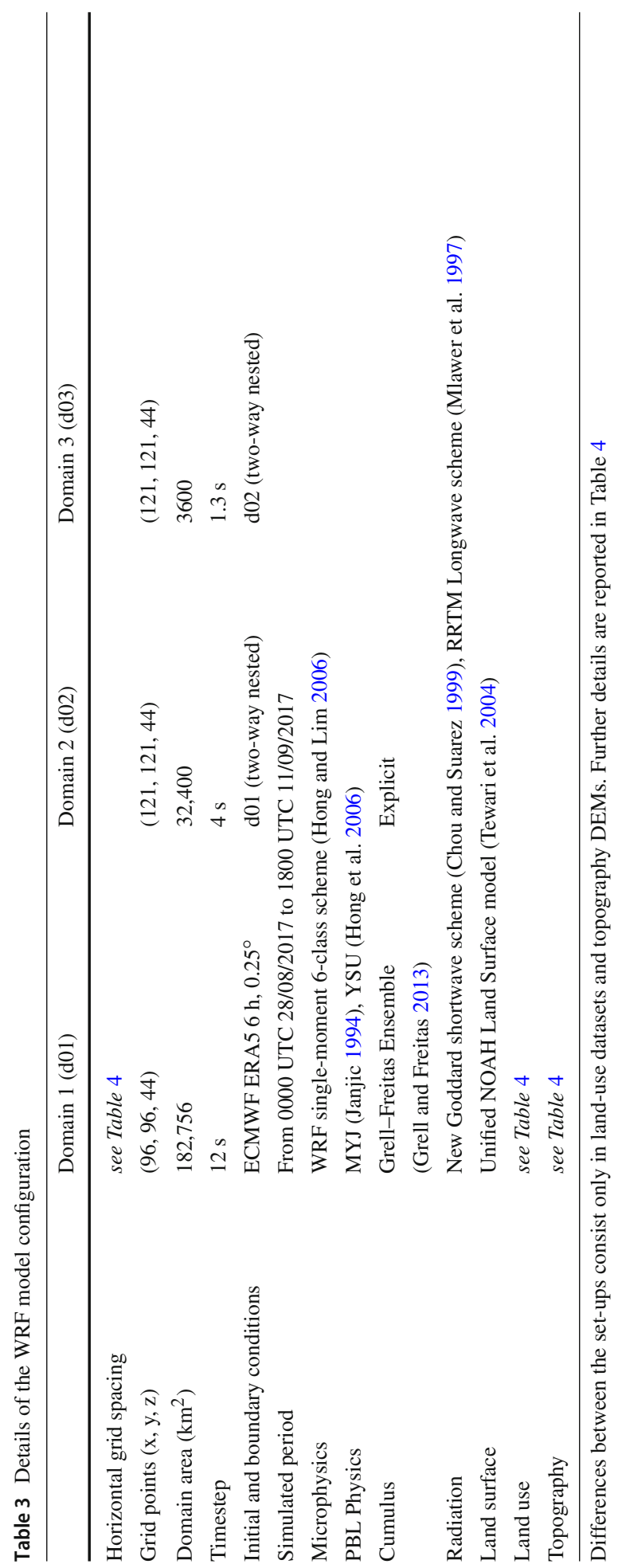


approximately around $5 \mathrm{~m}$ above ground level, and there were 13 levels within $1 \mathrm{~km}$ above the ground. The high-resolution level distribution caused numerical instability, as also noticed by Giovannini et al. (2014). However, by fine-tuning the model, especially several dynamics options and the timestep, it was possible to conclude the simulations successfully. The dynamics options of the WRF model were set by imposing a damping of the vertical velocity component and upper-bound 5-km implicit Rayleigh damping layer (Klemp et al. 2008). The model evaluated the second-order diffusion term on coordinate surfaces, and on domain d03 it computed a horizontal Smagorinsky first-order closure (Smagorinsky 1963).

Seven WRF model runs were performed with two main grid spacings in the inner domain: $1 \mathrm{~km}$ and $0.5 \mathrm{~km}$ using the parametrizations reported in Table 3; the only changes were the static data relative to topography, land-use description, and the PBL parametrization.

The combinations used are summarized in Table 4, and consisted of four land-use datasets and two different DEMs. More details are given in Sects. 2.3.1 and 2.3.2.

\subsubsection{Topography Datasets}

The WRF model is provided with several resolutions of DEM worldwide datasets, from 10 -arc-minutes to 30 -arc-seconds. The finest is at 30-arc-seconds and is known as GMTED 2010 (Global Multi-resolution Terrain Elevation Data, Danielson and Gesch 2011). In order to obtain higher resolutions, it was necessary to improve the input topography of the WRF model. Therefore, the DEM used for the WRF500 inner domain (d03) was the NASA SRTM at 3 -arc-seconds resolution (NASA-JPL 2013), which corresponds to about $90 \mathrm{~m}$ of resolution at Alpine arc latitudes $\left(45^{\circ} \mathrm{N}\right)$. From the global dataset of NASA SRTM, a Europe-wide subsection was made, and many tiles of $5^{\circ}$ each were created and adapted to the WRF Pre-processing System (WPS) binary format.

The DEMs were smoothed by the WPS using the smooth-desmooth special algorithm with one smooth pass. The choice of smoothing the DEM was to remove too-steep slopes that could cause problems when calculating the pressure gradients as height differences between neighbouring eta-levels (Doyle et al. 2013). The smoothing degree was chosen to avoid slopes steeper than $50^{\circ}$, and this choice was applied to all simulations.

\subsubsection{Land-Use Categories}

Another issue of static input data to the WRF model is the land-use description. The land-use datasets are maps at different resolutions that have a category number for each grid point. Those categories correspond to the surface type of a region (forest, grassland, urban area, water, bare ground, glacier, etc.) and also the cultivation or the density of buildings. The WRF model is provided with several land-use datasets. The most widely used is the USGS (24 categories, Anderson et al. 1976), and the default is MODIS30 (21 categories). Both land-use datasets have a resolution of 30 -arc-seconds that at a latitude of $45^{\circ} \mathrm{N}$ corresponds to about $900 \mathrm{~m}$. The WRF model is provided with a higher 15-arc-seconds resolution of the MODIS dataset, which corresponds to a grid spacing of about $450 \mathrm{~m}$ (MODIS15). Another dataset used is the CLC dataset (2012 version 18.5a, Büttner et al. 2014) that includes all previously stated information within 44 classes, and better describes the land use with a horizontal resolution of $100 \mathrm{~m}$ and a finer description of effective land use for the European region with respect to MODIS30, MODIS15, or USGS datasets (De Meij and Vinuesa 2014).

For each type of dataset, the WRF model interprets the land-use map using the land-use category table, which collects all the coefficients that describe the grid-point surface. This 


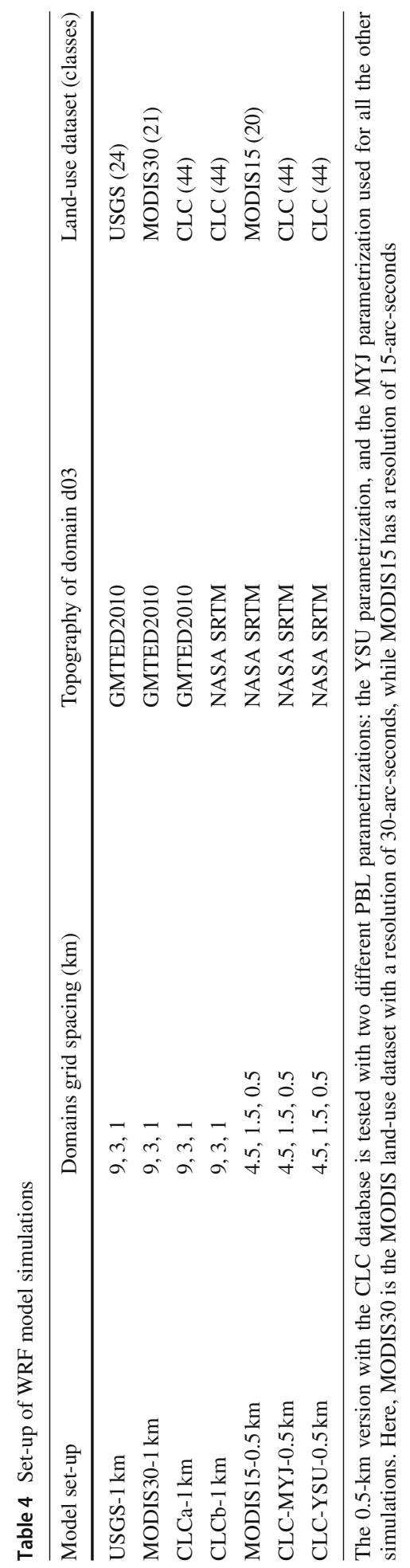


Table is divided into two seasons (summer and winter), and for each category the model has a set of seven physical characteristic parameters, used as initial and boundary conditions. They are: the roughness length $z_{0}$, thermal inertia $\lambda_{T}$, soil moisture availability $M$, albedo $\alpha$, surface heat capacity $C$, surface emissivity $\varepsilon$, and the parameter $S C F X$ representing the modification of the albedo due to fresh snow on each land-use category (Jiménez-Esteve 2015).

The WRF model's built-in datasets (USGS, MODIS30, and MODIS15) are global and in some cases obsolete, but over Europe the CLC maps can overcame that shortcoming. Here, the CLC dataset tiling over all of Europe into approximately $5^{\circ}$ tiles was implemented. The georeferenced TIFF images were converted into WPS binary files maintaining the 44 category classes of the original raster. In order to interpret the 44 CLC classes, the description of the dataset is essential.

Using remote-sensing instruments, Pineda et al. (2004) identified the surface parameters for the 44 CLC land-use categories (Table 1 in their article), even if some very similar CLC categories were treated as one single category (e.g., urban). Pineda et al. (2004) applied their land-use table into the MM5 meteorological model for testing the model performance over Spain, and established a correspondence between the CLC and USGS categories.

Due to the absence of a CLC land-use table in the WRF environment, some members of the WRF community (De Meij and Vinuesa 2014; Schicker et al. 2016; Gerber et al. 2018) used the CLC dataset without implementing the complete set of parameters suggested by Pineda et al. (2004) and only reclassified the raster dataset into the USGS land-use categories. In this way, from the original 44 classes of the CLC database the reclassified raster contained only 24 classes; however, some advantages of the CLC database were not lost, as with the higher resolution.

Here, we set up a novel implementation using the parameters in Pineda et al. (2004), and build a new land-use table for the WRF model, considering the full category description of the CLC database (44 classes). The snow-albedo effect and the surface emissivity that were not present in the Pineda et al. (2004) table and that are necessary in the WRF land-use table were derived from USGS land-use table using the correspondence between the categories.

Implementing this new land-use table was met with some difficulties, because directly connected to it is a WRF vegetation table. The vegetation table describes, for each land-use category, the vegetation-related parameters, such as the leaf area index, the minimum and maximum albedo (which changes with the season), the roughness length, and some plant functional types, including the root depth. Those specific parameters were not calculated by Pineda et al. (2004), so it was necessary to reclassify the USGS ones over the 44 CLC classes, following the correspondence suggested by Pineda et al. (2004).

\subsection{Methodology for Comparing Simulations with Observations}

Seven WRF model runs were compared with in situ measurements from five weather stations. The location of these limited number of stations was chosen to best represent the Forni Glacier area and the characteristics of the surrounding complex mountainous terrain. The overall parametrizations were kept constant (i.e., microphysics, radiation) while the land-use dataset, the grid spacing, and the topography were changed.

The first set of three simulations (Table 4), categorized as low-resolution, used the highest possible resolution allowed by the default topography (GMTED 2010) and land-use data (MODIS30, USGS, or CLC). The fourth simulation tested the NASA SRTM topography to ensure if the updated topography could enhance the WRF model performances. The last set 
of three simulations (Table 4), categorized as high-resolution, used the grid-spacing of $0.5 \mathrm{~km}$ with NASA SRTM topography and two different land-use datasets: CLC for the CLC- $0.5 \mathrm{~km}$ set-up and MODIS15 for the MODIS15-0.5 km set-up. The set-up, CLC-YSU-0.5 km, has the same static data configuration but with the YSU PBL parametrization (Hong et al. 2006) and the subgrid orographic wind drag activated, instead of the MYJ PBL parametrization as in all other simulations.

The WRF model runs at a horizontal resolution of $1 \mathrm{~km}$ have three two-way nested domains with 9,3 , and $1 \mathrm{~km}$ of grid spacing, whereas the high-resolution run has three two-way nested domains at $4.5,1.5$, and $0.5 \mathrm{~km}$ of grid spacing.

The assessment of model performance uses the data gathered in the previously listed weather stations (see Sect. 2.2). The parameters considered are the air temperature, wind speed, wind gust, and turbulent sensible heat flux, the latter only measured at the MiTo station. Simulated and measured data at station sites were averaged over 30-min intervals at the nearest grid point to the station. To strengthen the analysis, the most representative grid point was also considered, and was chosen among the eight nearest neighbours to the previously selected grid point in terms of land-use and topography characteristics. In Online Resource 2, the grid points selected are listed.

The analysis is performed on the third domain only, and the statistics considered are the bias $(B I A S)$, the root-mean-square error (RMSE), the mean absolute error $(M A E)$, and the squared correlation coefficient $R^{2}$ between simulated and observed values, where

$$
\begin{aligned}
B I A S & =\frac{\sum_{t=1}^{n}\left(O_{t}-E_{t}\right)}{n}, \\
R M S E & =\sqrt{\frac{\sum_{t=1}^{n}\left(O_{t}-E_{t}\right)^{2}}{n}}, \\
M A E & =\frac{\sum_{t=1}^{n}\left|O_{t}-E_{t}\right|}{n},
\end{aligned}
$$

and

$$
R^{2}=\frac{\sum_{t=1}^{n}\left(E_{t}-\bar{O}\right)^{2}}{\sum_{t=1}^{n}\left(O_{t}-\bar{O}\right)^{2}} .
$$

Here, $O_{t}$ are the observed values, $\bar{O}$ is the average of observed values, and $E_{t}$ are the estimated values from the WRF model.

In order to compare the WRF results with the observations, a post-processing of observations was needed, and is described next.

\subsubsection{Ultrasonic-Anemometer Data Analysis}

The ultrasonic-anemometer data needed post-processing before being compared with the WRF model data. In particular, the anemometer data need to be processed using a correction of the coordinate system considering the tilt measured by two inclinometers, and the true north angle, after the positioning of the instrument on a horizontal plane with a geographic reference system (Richiardone et al. 2008). Three different coordinate rotations are available to align the $x$-axis with the main wind direction (streamline coordinates), including double rotation (Tunner and Thurtell 1969), triple rotation (McMillen 1988; Cassardo et al. 1995), and the planar-fit method (Wilczak et al. 2001). Recently, Golzio et al. (2019) revealed that the double rotation and triple rotation were almost comparable in complex mountainous terrain, 
Table 5 Real station altitudes in $\mathrm{m}$ a.s.l. For the models, the altitude difference between the inner domain topography and the real are given in metres

\begin{tabular}{lcccccc}
\hline Station & Real & $\begin{array}{l}1 \mathrm{~km} \\
\text { GMTED2010 }\end{array}$ & $\begin{array}{l}1 \mathrm{~km} \\
\text { NASA-SRTM }\end{array}$ & $\begin{array}{l}0.5 \mathrm{~km} \\
\text { NASA-SRTM }\end{array}$ & \multicolumn{2}{c}{ Station displacement } \\
\hline AWS1 Forni & 2700 & 116.00 & 108.65 & -16.94 & 445 & 111 \\
MiTo & 2522 & 182.57 & 196.26 & -51.92 & 648 & 315 \\
Bormio & 1172 & 53.11 & 49.48 & 47.87 & 497 & 249 \\
Solda & 1907 & 280.99 & 245.89 & 40.78 & 712 & 222 \\
Careser & 2600 & -191.81 & -174.75 & 5.33 & 567 & 249 \\
\hline
\end{tabular}

The last two columns report the horizontal distances between the "central" grid point and the real position of the station in metres, for set-ups $1 \mathrm{~km}$ and $0.5 \mathrm{~km}$

while the planar fit could encounter huge difficulties into the determination of the streamline plane. For this reason, the double rotation was applied. Before applying the rotation, the raw signal was despiked and corrected for any transducer-temperature dependency using a previous quality-assessment campaign (Richiardone et al. 2012) and the procedure obtained after Stiperski and Rotach (2016) and described in Golzio et al. (2019). Fluxes were computed on 30-min moving windows, with an overlapped period of $15 \mathrm{~min}$, giving four flux values per hour.

\subsubsection{Wind Speed and Direction Measurements}

The weather stations with wind measurements were: MiTo, Bormio, and Careser. The MiTo and Careser stations were not WMO (World Meteorological Organisation) standard stations, because the distance to the ground from the anemometer is less than $10 \mathrm{~m}$. Therefore, the nearest model level is used to compare the measurements with the simulations. The anemometer heights were respectively 2,10 , and $5 \mathrm{~m}$, the nearest model levels in the 0.5 -km set-up are at 4.6, 10, and $4.5 \mathrm{~m}$, and $4.5,10$, and $4.6 \mathrm{~m}$ for the 1-km set-up.

The wind gusts are defined as the maximum wind speed in a 30-min interval. The WRF model output is given every timestep (around $1 \mathrm{~s}$ ), so the wind gust is computed as the maximum wind speed among 1800 values $(30 \mathrm{~min}$ ). The weather station observations were provided with the wind gust into output datafiles, usually the measurement interval of the weather station data is about 1 to $3 \mathrm{~s}$.

\subsubsection{Temperature Measurements}

The temperature is strongly altitude dependent: for this reason, it was decided to compute the temperature at the observation points using a moist adiabatic lapse rate $\left(0.0065 \mathrm{~K} \mathrm{~m}^{-1}\right)$ following the approach of Schicker et al. (2016). Table 5 shows the real elevation a.s.l. of the selected stations, and in the following columns the difference of the WRF ground to the real altitude is shown.

The comparison between the model and the observation considers the nearest grid point to the station coordinates. Sometimes it could be possible that the nearest grid point is not the most representative of the station location due to the intrinsic discretization and approximation by the model. For this reason, the eight nearest neighbours of the selected grid point (called central) are also considered. However, for the 1-km set-up, the total area of those nine points 
is $9 \mathrm{~km}^{2}$, four times bigger with respect to the $0.5-\mathrm{km}$ set-up. The eight nearest neighbours are defined using cardinal points with respect to the central grid point.

\section{Results and Discussion}

\subsection{Topography and Land-Use Improvements}

The first improvement concerns the major accuracy of the topography by using the updated DEM (NASA SRTM) with respect to the default (GMTED2010). Even after the smoothing and the interpolation to the model grid scale computed by the WPS, the NASA SRTM DEM is more similar to the real topography, represented by the regional DEM at 10-m resolution, as regards the default one, and confirms the better representation of valley bottom and mountain peaks. In fact, the comparison at the highest resolution of the inner domain gives an average lowering of the valley bottom between 30 and $90 \mathrm{~m}$, while mountain peaks on average increase between 60 and $150 \mathrm{~m}$. Figure 3 shows the difference between the updated and default DEMs, with negative values meaning the default DEM has a higher altitude, whereas positive values indicate that the updated DEM has a higher altitude. These enhancements could be very important for a correct interpretation of the landscape and, from the model point-of-view, they can improve the calculation of meteorological parameters, especially those directly related with the terrain shape. Moreover, a comparison between the measured topography and the model (NASA SRTM) topography was performed. This shows that the valley floor is $20 \mathrm{~m}$ to $60 \mathrm{~m}$ higher in the model compared with the measured topography, and mountain peaks are lowered by about $80 \mathrm{~m}$ to $120 \mathrm{~m}$ in the model with respect to the measured topography. Table 5 shows the enhanced accuracy of the $0.5-\mathrm{km}$ set-up with the updated topography at the station sites. The differences between real and model altitudes are much smaller in the $0.5-\mathrm{km}$ set-up, ranging in absolute values between $5 \mathrm{~m}$ to $52 \mathrm{~m}$. In the 1-km set-up with default topography, the differences range between $53 \mathrm{~m}$ to $281 \mathrm{~m}$, but for the updated topography, the differences are $49 \mathrm{~m}$ to $246 \mathrm{~m}$, which is lower than the default topography at the same resolution. The increase in accuracy is the result of both the topography dataset and maily by the horizontal grid-size.

Considering only the innermost domain (d03), the improvements in land use are immediately recognizable. In Fig. 4, the land-use fields for CLC, MODIS15, USGS, and MODIS30 are shown.

The CLC raster depicts the altitudinal distribution of vegetation well, passing from evergreen needleleaf forest (category 24) to grassland, then bare ground and at the top of some mountain areas, ice and perennial snow; at valley bottoms are croplands, agriculture, and cities. The most similar land use to the complexity reached by the CLC dataset is MODIS15 (Fig. 4b), but grassland (category 10) is too widespread, and the bare ground is not represented, while the glacier extension is comparable to the real nowadays extention and to the CLC snow and ice category. Moreover, the MODIS15 land use does not consider the inland water category, but only the "sea and ocean" one. The MODIS30 land use (Fig. 4d) distributes the forest and the wooded tundra randomly. The glacier extension is outlined quite correctly and is not overestimated as it is in the USGS land use (Fig. 4c). The USGS land use gives a patchwork behaviour, with dry land (category 2) mixed with evergreen forest (category 14), and the wooded tundra is overestimated.

Focusing on the urban categories, Bormio village $\left(10.366^{\circ} \mathrm{E}, 46.454^{\circ} \mathrm{N}\right)$ is the biggest built-up area included in the domain. The CLC land-use category 2 and MODIS 15 category 13 


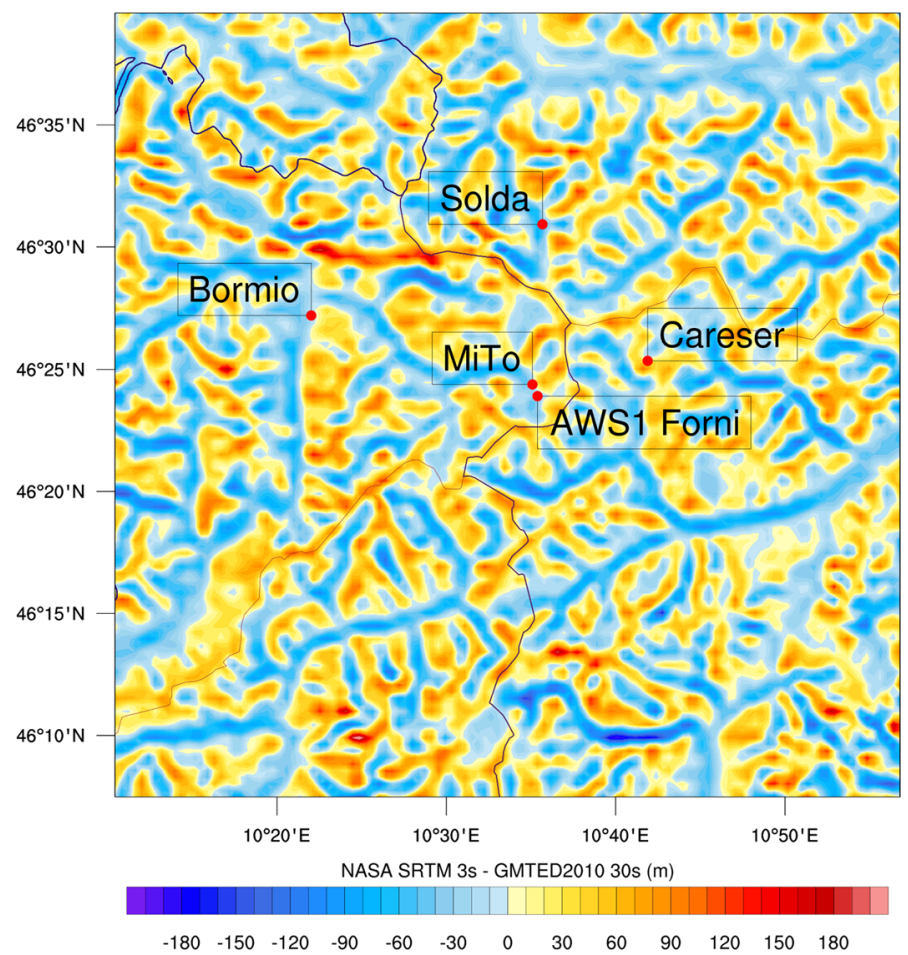

Fig. 3 The difference between the DEM at 3-arc-seconds (NASA SRTM) and the default DEM (GMTED2010) for the inner domain (d03). Blueish colours indicate a lower altitude from the NASA SRTM data, while reddish colours indicate higher altitude from NASA SRTM, with respect to the default

positioned Bormio well at the confluence of Valfurva Valley and Valdidentro Valley, while the MODIS30 land use (category 13) overestimates the village size and positioned it too much on the north side near the Stelvio Pass $\left(10.450^{\circ} \mathrm{E}, 46.533^{\circ} \mathrm{N}\right)$. Moreover, with the USGS land use (category 1), Bormio is not resolved. Furthermore, some categories represented in the USGS and MODIS datasets are inappropriate to mid-latitude terrain, and they do not correspond to the CLC representation of the same area.

The land-use correspondences between CLC top categories and MODIS or USGS top categories are summarized in Table 6, while the complete correspondences are reported in the Online Resources 1. In particular, the reclassification over the study area left out, or represented with an erroneous category, eleven USGS categories and nine MODIS30 and MODIS15 categories, which are reported as NRC (not represented classes) in Table 6.

The missing or misrepresented classes of CLC reclassification by the USGS, MODIS30 or MODIS15 land uses represent, respectively, 29.7\%, $11.8 \%$, and $4.7 \%$ of the study area. The magnitudes of not represented area in the MODIS30 land use is $425 \mathrm{~km}^{2}, 1070 \mathrm{~km}^{2}$ for the USGS land use, and $169 \mathrm{~km}^{2}$ for the MODIS15 land use. The most widespread classes left out or differently represented in the MODIS30 land use with respect to CLC are 18, "Wooded Tundra", and 8, "Woody Savannahs". Those two classes in fact are not suitable for alpine territories. In MODIS15 the most widespread excluded category is 14, "Cropland/grassland mosaic". For the USGS land use, the most widespread excluded classes are 21, "Wooded Tundra", 8 "Shrubland", 18 "Wooded wetland", and 5 "Cropland/grassland 
Table 6 Land-use top-class correspondence after Pineda et al. (2004) concerning the inner domain d03

\begin{tabular}{|c|c|c|c|c|c|}
\hline N. CLC & N. class & Category description & N. of tiles & Area $\left(\mathrm{km}^{2}\right)$ & $\%$ of domain \\
\hline \multicolumn{6}{|c|}{ CLC 2012} \\
\hline $1-11$ & & Urban & 120 & 30 & 0.8 \\
\hline 24 & & Coniferous forest & 4550 & 1138 & 31.6 \\
\hline 26 & & Natural grasslands & 1736 & 434 & 12.1 \\
\hline 31 & & Bare rocks & 3186 & 797 & 22.1 \\
\hline 32 & & Sparsely vegetated & 1668 & 417 & 11.6 \\
\hline 34 & & Glaciers and perpetual snow & 462 & 116 & 3.2 \\
\hline $40-43$ & & Inland water bodies & 36 & 9 & 0.3 \\
\hline \multicolumn{6}{|l|}{$\cdots$} \\
\hline Total & & & 14,400 & 3600 & 100.0 \\
\hline \multicolumn{6}{|c|}{ USGS, old WRF default } \\
\hline $1-11$ & 1 & Urban and built-up & 0 & 0 & 0.0 \\
\hline 24 & 14 & Evergreen needleleaf forest & 479 & 479 & 13.3 \\
\hline 26 & 7 & Grassland & 612 & 612 & 17.0 \\
\hline $30-33$ & 19 & Barren or sparsely vegetated & 31 & 31 & 0.9 \\
\hline 34 & 24 & Snow or ice & 127 & 127 & 3.5 \\
\hline $40-44$ & 16 & Water bodies & 7 & 7 & 0.2 \\
\hline \multicolumn{6}{|l|}{$\ldots$} \\
\hline Total & & & 2530 & 2530 & 70.3 \\
\hline NRC & 11 & $4,5,8,10,12,13,18,20-23$ & 1070 & 1070 & 29.7 \\
\hline \multicolumn{6}{|c|}{ MODIS30, WRF version 3.9.1 default } \\
\hline $1-11$ & 13 & Urban and built-up & 44 & 44 & 1.2 \\
\hline 24 & 1 & Evergreen needleleaf forest & 828 & 828 & 23.0 \\
\hline 26 & 10 & Grasslands & 381 & 381 & 10.6 \\
\hline $30-33$ & 16 & Barren or sparsely vegetated & 41 & 41 & 1.1 \\
\hline 34 & 15 & Snow and ice & 40 & 40 & 1.1 \\
\hline $40-43$ & 21 & Inland water bodies (lakes) & 10 & 10 & 0.3 \\
\hline \multicolumn{6}{|l|}{$\cdots$} \\
\hline Total & & & 3175 & 3175 & 88.2 \\
\hline NRC & 9 & $2,3,6,8,9,14,18-20$ & 425 & 425 & 11.8 \\
\hline \multicolumn{6}{|c|}{ MODIS15 } \\
\hline $1-11$ & 13 & Urban and built-up & 30 & 8 & 0.2 \\
\hline 24 & 1 & Evergreen needleleaf foreset & 2401 & 600 & 16.7 \\
\hline 26 & 10 & Grasslands & 7047 & 1762 & 48.9 \\
\hline $30-33$ & 16 & Barren or sparsely vegetated & 139 & 35 & 1.0 \\
\hline 34 & 15 & Snow and ice & 577 & 144 & 4.0 \\
\hline $40-43$ & 17 & Water bodies & 173 & 43 & 1.2 \\
\hline \multicolumn{6}{|l|}{$\ldots$} \\
\hline Total & & & 13,724 & 3431 & 95.3 \\
\hline $\mathrm{NRC}$ & 9 & $2,3,6,8,9,14,18-20$ & 676 & 169 & 4.7 \\
\hline
\end{tabular}

We consider the CLC land use with 44 classes (resolution of $100 \mathrm{~m}$ ), USGS land use with 24 classes, MODIS30 land use with 21 classes (lakes description and 30-arc-seconds resolution, and default for the WRF model 3.9.1), and the MODIS15 land use with 20 classes (without a separate category for lakes and a resolution of 15-arc-second). The abbreviations "N." means number and NRC stands for "not represented classes" into the CLC land use that, instead, are present in the MODIS or USGS land uses 

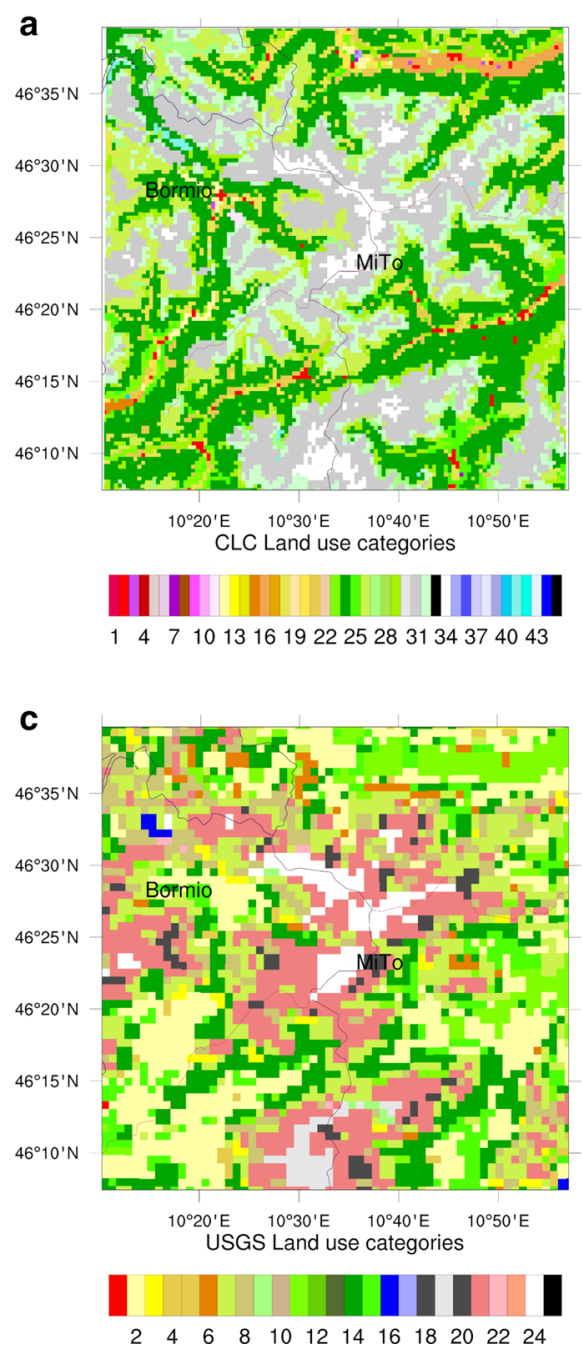
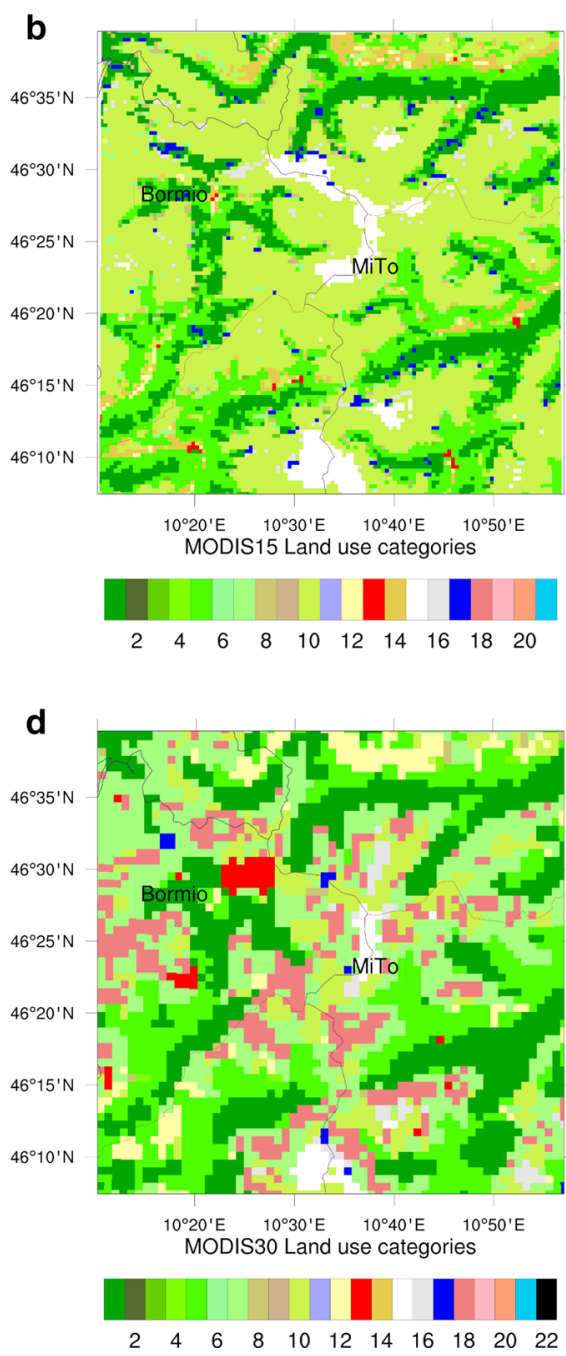

Fig. 4 The different land-use datasets for the inner domain (d03) whose area is $3600 \mathrm{~km}^{2}$. a CLC land use with 44 categories; b MODIS 15 land use (the higher resolution dataset included in the WRF model); c USGS land use, the old default of the WRF model; $\mathbf{d}$ MODIS30 land use, the default of the WRF model (version 3.9.1). Two red dots indicates the positions of the Bormio (on the left) and MiTo stations, the latter being the weather station installed during this campaign at the Forni Glacier foreland. Similar colours represent similar or identical land-use categories, i.e., the urban build-up category is red

mosaic". Concluding, the use of the CLC raster file enhances the spatial resolution, but the reclassification method (Schicker et al. 2016; De Meij and Vinuesa 2014; Gerber et al. 2018) leaves out many peculiar classes due to the reduction from the 44 CLC classes to the 24 USGS classes. Here, a completion of the Pineda et al. (2004) Table 1 with 44 land-use classes, full coefficient descriptions, and no reclassification is applied. 


\subsection{Comparison of Observations with Simulations}

Five weather stations (Sect. 2) surrounded the study area and permit the comparison of the WRF output with in situ observations, including the temperature at $2 \mathrm{~m}$, wind speed and direction, and THE sensible heat flux. In Sect. 3.3, the WRF simulations are compared, considering the resolution (grid-spacing), topography, land use, and PBL parametrizations separately.

\subsubsection{Temperature}

All weather stations measured temperature. Table 7 presents the statistics from the nearest grid point to the station coordinates, with the values of BIAS, MAE and RMSE for the mean, maximum, and minimum temperature over 30-min windows; the values using the best landuse and topography point are reported in Online Resource 2. Considering all simulations, the mean temperature has a value of BIAS (Table 7) ranging between -1.5 and $4.4{ }^{\circ} \mathrm{C}$, and the difference between the value of BIAS at each station is less than $3.1{ }^{\circ} \mathrm{C}$, reached at Bormio. The value of $R M S E$ ranged from 1.1 to $5.2^{\circ} \mathrm{C}$, the maximum variation between simulations is registered at Bormio $\left(2.9^{\circ} \mathrm{C}\right)$ and the minimum at the AWS1 Forni station $\left(0.7^{\circ} \mathrm{C}\right)$. The correlation coefficient $R^{2}$ ranges from 0.54 to 0.94 . The comparison between the observed and simulated mean temperature shows that at some geographical locations the simulations produce comparable values, while elsewhere (for example at Bormio) the results are significantly different. The simulations of the maximum and minimum daily temperature at the AWS1 Forni and MiTo stations do not show significant differences between the simulations.

\subsubsection{Wind Speed and Direction}

Three weather stations in the study area were equipped to measure the wind speed and direction: Bormio, MiTo, and Careser. The comparison with observations is made by extracting the velocity components ( $u$ and $v$ ) from the nearest model level to the station anemometer height, as described in Sect. 2.4.2, to obtain a more reliable result for the comparison. Presented in Table 8 are the values of BIAS, RMSE and MAE between the nearest neighbour grid point and the station location.

The wind-speed BIAS ranges from -2.9 to $0.4 \mathrm{~m} \mathrm{~s}^{-1}$, the sign is always negative, so the simulated values underestimate the observation, the only exception is for the CLC-YSU$0.5 \mathrm{~km}$ results at the MiTo station where the simulation overestimates the observations. The value of RMSE ranges from 1.9 to $4.1 \mathrm{~m} \mathrm{~s}^{-1}$, while wind gusts have values of RMSE from 2.1 to $4.3 \mathrm{~m} \mathrm{~s}^{-1}$. The wind direction has a value of BIAS from $-6^{\circ}$ to $4^{\circ}$, and a relatively high value of $R M S E$, from $6^{\circ}$ to $21^{\circ}$, with the maximum values at Bormio station.

We investigate the wind-speed profiles obtained from the $0.5-\mathrm{km}$ set-up, with the aim of detecting the glacier katabatic flow with the model and explaining the night-time negative sensible heat fluxes (see Sect. 3.2.3). The vertical profile at the MiTo station is shown in Fig. 5, depicting a typical mountain breeze pattern, with daytime upvalley flow (positive values) and night-time downvalley flow (negative values). Note that the upper valley is on the right and the valley exit is on the left. The valley is approximately oriented north-north-west-southsouth-east, with the glacier on the south-south-east side (upvalley) and the foreland in the north-north-west side (downvalley). Consequently, the upvalley flow comes from the northnorth-west and the downvalley flow from the south-south-east. Figure 5 shows the upwalley 
Table 7 Model performances regarding temperature ( $T_{m}$ mean, $T_{x}$ maximum, $T_{n}$ minimum temperatures) with respect to the five measurement locations

\begin{tabular}{|c|c|c|c|c|c|c|c|c|}
\hline \multicolumn{2}{|l|}{${ }^{\circ} \mathrm{C}$} & $\begin{array}{l}\text { MODIS30 } \\
-1 \mathrm{~km}\end{array}$ & $\begin{array}{l}\text { USGS } \\
-1 \mathrm{~km}\end{array}$ & $\begin{array}{l}\text { CLCa } \\
-1 \mathrm{~km}\end{array}$ & $\begin{array}{l}\text { CLCb } \\
-1 \mathrm{~km}\end{array}$ & $\begin{array}{l}\text { MODIS } 15 \\
-0.5 \mathrm{~km}\end{array}$ & $\begin{array}{l}\text { CLC-MYJ } \\
-0.5 \mathrm{~km}\end{array}$ & $\begin{array}{l}\text { CLC-YSU } \\
-0.5 \mathrm{~km}\end{array}$ \\
\hline \multicolumn{9}{|c|}{ AWS1 Forni } \\
\hline \multirow[t]{4}{*}{$T_{m}$} & $B I A S$ & 0.2 & -1.3 & -0.5 & -1.3 & -1.2 & -0.8 & -1.5 \\
\hline & $R M S E$ & 1.4 & 2.0 & 1.6 & 2.0 & 1.9 & 1.4 & 2.1 \\
\hline & $M A E$ & 1.0 & 1.6 & 1.2 & 1.6 & 1.5 & 1.2 & 1.7 \\
\hline & $R^{2}$ & 0.88 & 0.81 & 0.83 & 0.82 & 0.85 & 0.86 & 0.83 \\
\hline \multirow[t]{3}{*}{$T_{x}$} & $B I A S$ & -0.3 & -1.8 & -1.1 & -1.8 & -1.6 & -1.3 & -2.0 \\
\hline & $R M S E$ & 1.7 & 2.6 & 2.1 & 2.6 & 2.4 & 2.1 & 2.6 \\
\hline & $M A E$ & 1.2 & 2.0 & 1.5 & 2.0 & 1.9 & 1.6 & 2.1 \\
\hline \multirow[t]{3}{*}{$T_{n}$} & $B I A S$ & -0.6 & -0.8 & -0.1 & -0.8 & -0.9 & -0.4 & -1.0 \\
\hline & $R M S E$ & 1.4 & 1.7 & 1.4 & 1.7 & 1.6 & 1.3 & 1.8 \\
\hline & $M A E$ & 1.1 & 1.3 & 1.1 & 1.3 & 1.3 & 0.9 & 1.4 \\
\hline \multicolumn{9}{|c|}{ MiTo } \\
\hline \multirow[t]{4}{*}{$T_{m}$} & $B I A S$ & 0.7 & -1.0 & 1.1 & -0.5 & 0.5 & 1.2 & 1.0 \\
\hline & $R M S E$ & 1.9 & 2.6 & 2.3 & 2.1 & 1.7 & 2.1 & 2.0 \\
\hline & $M A E$ & 1.5 & 2.0 & 1.9 & 1.6 & 1.4 & 1.8 & 1.7 \\
\hline & $R^{2}$ & 0.85 & 0.72 & 0.80 & 0.79 & 0.86 & 0.85 & 0.84 \\
\hline \multirow[t]{3}{*}{$T_{x}$} & $B I A S$ & -0.5 & -1.1 & -0.6 & -0.7 & 0.4 & 1.0 & 0.8 \\
\hline & $R M S E$ & 2.0 & 2.8 & 2.2 & 2.3 & 1.9 & 2.1 & 2.0 \\
\hline & $M A E$ & 1.6 & 2.1 & 1.6 & 1.7 & 1.5 & 1.7 & 1.7 \\
\hline \multirow[t]{3}{*}{$T_{n}$} & $B I A S$ & 0.8 & -0.9 & -0.2 & -0.3 & 0.6 & 1.4 & 1.2 \\
\hline & $R M S E$ & 1.8 & 2.5 & 2.0 & 2.0 & 1.7 & 2.2 & 2.1 \\
\hline & $M A E$ & 1.5 & 1.9 & 1.5 & 1.6 & 1.3 & 1.8 & 1.8 \\
\hline \multicolumn{9}{|c|}{ Bormio } \\
\hline \multirow[t]{4}{*}{$T_{m}$} & $B I A S$ & 1.6 & 1.4 & 4.4 & 4.4 & 1.3 & 3.2 & 3.1 \\
\hline & $R M S E$ & 2.5 & 2.3 & 5.2 & 5.2 & 2.6 & 4.0 & 3.9 \\
\hline & $M A E$ & 2.0 & 1.9 & 4.4 & 2.1 & 2.0 & 3.2 & 3.2 \\
\hline & $R^{2}$ & 0.79 & 0.78 & 0.55 & 0.54 & 0.72 & 0.63 & 0.66 \\
\hline \multicolumn{9}{|c|}{ Solda } \\
\hline \multirow[t]{4}{*}{$T_{m}$} & $B I A S$ & 0.9 & 1.1 & 2.7 & 1.5 & 0.6 & 2.5 & 2.1 \\
\hline & $R M S E$ & 2.1 & 2.1 & 3.5 & 2.7 & 1.9 & 3.2 & 2.8 \\
\hline & $M A E$ & 1.6 & 1.6 & 2.9 & 2.2 & 1.5 & 2.7 & 2.3 \\
\hline & $R^{2}$ & 0.84 & 0.80 & 0.79 & 0.79 & 0.86 & 0.83 & 0.84 \\
\hline \multicolumn{9}{|c|}{ Careser } \\
\hline \multirow[t]{4}{*}{$T_{m}$} & $B I A S$ & -0.4 & -0.5 & 0.7 & 1.9 & -0.7 & -0.1 & -0.4 \\
\hline & $R M S E$ & 1.2 & 1.2 & 1.4 & 2.2 & 1.2 & 1.1 & 1.1 \\
\hline & $M A E$ & 0.9 & 0.9 & 1.1 & 2.0 & 1.0 & 0.8 & 1.9 \\
\hline & $R^{2}$ & 0.93 & 0.94 & 0.92 & 0.92 & 0.94 & 0.94 & 0.94 \\
\hline
\end{tabular}

Regarding the mean temperature, the squared correlation coefficient $R^{2}$ of the observed versus simulated data is displayed. Presented are the statistics of the nearest grid point to station locations. Statistics were computed over 720 30-min values, best statistics are in bold, while worst statistics are in italic font 

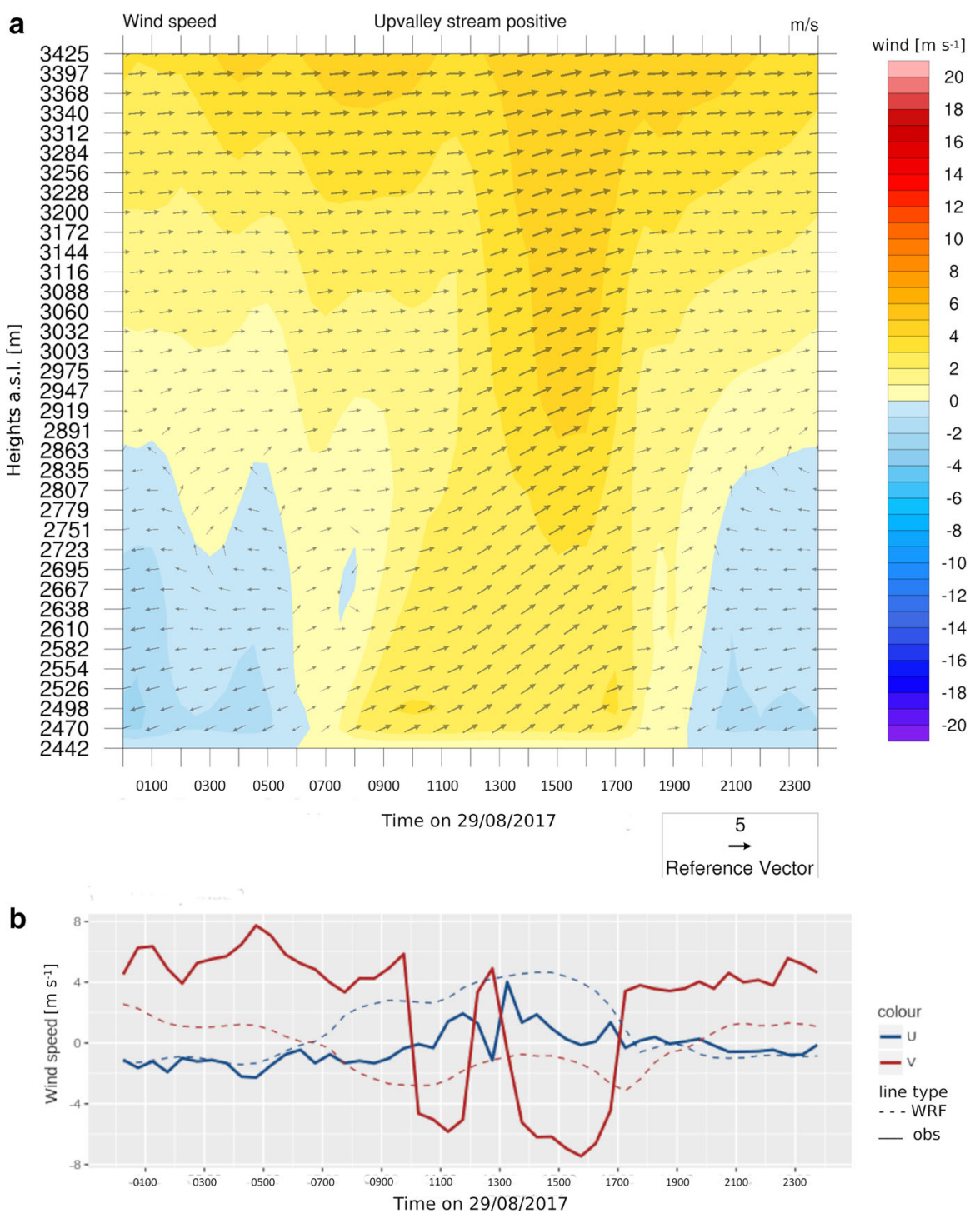

Fig. 5 a Vertical profile of the along valley velocity component over the MiTo station. On the $y$-axis the altitude, interpolated from vertical levels output of the CLC-MYJ-0.5 km set-up is reported, while on the $x$ axis is the time of day on 29 August 2017. Positive contour values indicate up valley flow, and arrows indicate the velocity vectors along the valley axis and the vertical velocity component. Arrows pointing to the right indicate up valley flow, whereas arrows pointing to the left indicate down valley flow. The crest top is around 3200-3300 m a.s.1. b The velocity components ( $u$ and $v$ ) measured (solid line) and simulated (dashed line) at MiTo station during the same day 
Table 8 Wind speed $\left(\mathrm{m} \mathrm{s}^{-1}\right)$, wind gust $\left(\mathrm{m} \mathrm{s}^{-1}\right)$, and wind direction (Dir., ${ }^{\circ}$ ) comparison between the seven tested WRF set-ups

\begin{tabular}{lllllll} 
MODIS30 & USGS & CLCa & CLCb & MODIS15 & CLC & CLC \\
$-1 \mathrm{~km}$ & $-1 \mathrm{~km}$ & $-1 \mathrm{~km}$ & $-1 \mathrm{~km}$ & $-0.5 \mathrm{~km}$ & - MYJ & - YSU \\
& & & & & $-0.5 \mathrm{~km}$ & $-0.5 \mathrm{~km}$ \\
\hline
\end{tabular}

\begin{tabular}{|c|c|c|c|c|c|c|c|c|}
\hline \multicolumn{9}{|c|}{$\operatorname{MiTo}(2 \mathrm{~m})$} \\
\hline \multirow[t]{3}{*}{ Speed } & BIAS & -1.0 & -1.2 & -0.8 & -0.6 & -1.1 & -0.3 & 0.4 \\
\hline & RMSE & 2.9 & 3.1 & 2.6 & 2.4 & 3.0 & 2.6 & 1.9 \\
\hline & $M A E$ & 2.2 & 2.2 & 1.9 & 1.8 & 2.1 & 1.9 & 1.5 \\
\hline \multirow[t]{3}{*}{ Gust } & $B I A S$ & 0.8 & 0.6 & 1.3 & 1.6 & 0.3 & -1.7 & -2.6 \\
\hline & $R M S E$ & 3.1 & 3.1 & 3.1 & 3.2 & 3.1 & 3.4 & 3.6 \\
\hline & $M A E$ & 2.3 & 2.2 & 2.4 & 2.4 & 2.2 & 2.6 & 2.8 \\
\hline \multirow[t]{3}{*}{ Dir. } & $B I A S$ & -2 & -1 & -1 & -1 & -3 & -3 & -2 \\
\hline & $R M S E$ & 8 & 11 & 7 & 6 & 9 & 10 & 6 \\
\hline & $M A E$ & 5 & 6 & 4 & 4 & 5 & 5 & 3 \\
\hline \multicolumn{9}{|c|}{ Bormio $(10 \mathrm{~m})$} \\
\hline \multirow[t]{3}{*}{ Speed } & $B I A S$ & -1.4 & -1.4 & -0.7 & -0.6 & -1.2 & -1.4 & -0.8 \\
\hline & $R M S E$ & 2.6 & 2.7 & 2.0 & 2.0 & 2.4 & 2.5 & 2.0 \\
\hline & $M A E$ & 1.8 & 1.8 & 1.4 & 1.4 & 1.7 & 1.7 & 1.5 \\
\hline \multirow[t]{3}{*}{ Gust } & $B I A S$ & -1.7 & -1.7 & -0.6 & -0.5 & -1.7 & -1.7 & -1.6 \\
\hline & $R M S E$ & 2.9 & 3.0 & 2.1 & 2.1 & 2.9 & 2.6 & 2.1 \\
\hline & $M A E$ & 2.0 & 2.0 & 1.5 & 1.5 & 2.1 & 1.8 & 1.6 \\
\hline \multirow[t]{3}{*}{ Dir. } & $B I A S$ & 3 & 3 & 2 & 3 & 4 & 4 & 3 \\
\hline & $R M S E$ & 21 & 20 & 14 & 14 & 19 & 21 & 16 \\
\hline & $M A E$ & 10 & 9 & 6 & 6 & 8 & 10 & 7 \\
\hline \multicolumn{9}{|c|}{ Careser $(5 \mathrm{~m})$} \\
\hline \multirow[t]{3}{*}{ Speed } & $B I A S$ & -1.9 & -1.7 & -2.9 & -2.8 & -2.6 & -2.7 & -1.4 \\
\hline & $R M S E$ & 2.9 & 2.7 & 4.1 & 4.0 & 3.7 & 4.0 & 2.5 \\
\hline & $M A E$ & 2.1 & 2.0 & 3.1 & 3.0 & 2.8 & 2.9 & 1.8 \\
\hline \multirow[t]{3}{*}{ Gust } & $B I A S$ & -2.3 & -2.0 & -2.9 & -2.8 & -3.3 & -2.8 & -1.3 \\
\hline & $R M S E$ & 3.2 & 2.9 & 4.0 & 4.0 & 4.3 & 4.1 & 2.6 \\
\hline & $M A E$ & 2.5 & 2.3 & 3.1 & 3.0 & 3.5 & 3.1 & 1.9 \\
\hline \multirow[t]{3}{*}{ Dir. } & $B I A S$ & -4 & -3 & -6 & -5 & -3 & -3 & -3 \\
\hline & $R M S E$ & 10 & 8 & 12 & 11 & 10 & 9 & 9 \\
\hline & $M A E$ & 5 & 3 & 7 & 6 & 6 & 5 & 5 \\
\hline
\end{tabular}

As done for temperatures, the optimum values of $R M S E$ are in bold, the worst in italic font. The statistics are referred to the nearest grid point to station locations

flow between 0600 to 1930 UTC and the downvalley flow during the night. The downvalley circulation only reaches $2800 \mathrm{~m}$ a.s.l. and, considering the orography of the valley with a crest top between $3200 \mathrm{~m}$ a.s.l. and $3600 \mathrm{~m}$ a.s.l., does not fill the valley, probably as a consequence of a synoptic flow aloft in the upvalley direction. This flow is also observed in the wind direction measured by the MiTo station, as shown in Fig. 5b. On 29 August, the night-time $u$ component is perfectly simulated, while the daytime $u$ component is too positive with respect to the observations. Absolute values of the $v$ component are always lower than 
Table 9 Sensible heat flux RMSE statistics for the nearest-neighbour grid point to the MiTo station and for the optimum land-use and topography grid point, chosen following Online Resource 2

\begin{tabular}{llllllll}
\hline $\mathrm{W} \mathrm{m}^{-2}$ & $\begin{array}{l}\text { MODIS30 } \\
-1 \mathrm{~km}\end{array}$ & $\begin{array}{l}\text { USGS } \\
-1 \mathrm{~km}\end{array}$ & $\begin{array}{l}\text { CLCa } \\
-1 \mathrm{~km}\end{array}$ & $\begin{array}{l}\text { CLCb } \\
-1 \mathrm{~km}\end{array}$ & $\begin{array}{l}\text { MODIS15 } \\
-0.5 \mathrm{~km}\end{array}$ & $\begin{array}{l}\text { CLC-MYJ } \\
-0.5 \mathrm{~km}\end{array}$ & $\begin{array}{l}\text { CLC-YSU } \\
-0.5 \mathrm{~km}\end{array}$ \\
\hline RMSE & 93 & $\mathbf{5 2}$ & 68 & 67 & 90 & 69 & $\mathbf{6 5}$ \\
RMSE (optimum) & 89 & 82 & 69 & $\mathbf{6 7}$ & 95 & 68 & $\mathbf{6 3}$ \\
\hline
\end{tabular}

The statistics are computed only in the selected clear-sky days, i.e. the nine days selected for the analysis of the typical day (Fig. 6)

measured values, generally following the observed trend. However, the general flow is well simulated by the $0.5-\mathrm{km}$ set-up, while the timing of the flow reversal (from upvalley to downvalley and vice versa) is better identified in the CLC-based runs, showing the influence of the land-use description. In contrast, the 1-km runs do not capture the flow reversal (not shown). In fact, the WPS maps of topography reveal that the Forni Valley is poorly resolved by the $1-\mathrm{km}$ set-up, while in comparison, the $0.5-\mathrm{km}$ set-up topography enhances the position and orientation of the valley.

\subsubsection{Sensible Heat Flux at Forni Glacier Foreland}

Sensible heat fluxes at MiTo station are compared with the model output at the nearest grid point to the station location and for the best nearest-neighbour point (following Table 14 in Online Resources 2). To avoid errors in measurements, due to harsh weather conditions (e.g. rain or snow), only fair-weather conditions (using flow pattern data, net radiation, the synoptic situation and images of the sky nearby) are considered, resulting in the selection of nine days from 28 to 30 August, and from 5 to 9 and 11 September.

In Table 9, the value of RMSE for the seven WRF simulations ranges from 52 to $93 \mathrm{~W} \mathrm{~m}^{-2}$, while considering the best grid point (selected among the nearest neighbours) the RMSE ranges from 63 to $95 \mathrm{~W} \mathrm{~m}^{-2}$.

The daily evolution of sensible heat fluxes (Fig. 6) shows that, at night, all simulations produce negative values in the range of 0 to $-25 \mathrm{~W} \mathrm{~m}^{2}$, while measurements are generally lower in the range of $-25 \mathrm{~W} \mathrm{~m}^{2}$ to $-50 \mathrm{~W} \mathrm{~m}^{2}$. The diurnal evolution of the sensible heat flux calculated by all the simulations, with the exception of USGS-1 km, shows the typical behaviour, with maximum values between $120 \mathrm{~W} \mathrm{~m}^{2}$ to $220 \mathrm{~W} \mathrm{~m}^{2}$ near noon. However, the comparison with the measurements shows a general overestimation of the fluxes. The whole set of simulations using the CLC land use produce similar results computing the sensible heat flux values much closer to measured ones than the sensible heat flux values simulated using the MODIS30, MODIS15, or USGS land-use datasets. During the night, all models overestimate sensible heat fluxes, in particular the CLC-YSU- $0.5 \mathrm{~km}$ results show about $0 \mathrm{~W} \mathrm{~m} \mathrm{~m}^{2}$. The land use is a key factor since all simulations using the same land use (CLC) yield similar results.

The measured sensible heat flux appears to contain contributions from both the glacier and bare or sparsely vegetated ground, thus with lower night-time and daytime values. To further inspect this particular trend, the flux footprint is investigated with the model of Kljun et al. (2002), and if the assumptions behind the Kljun et al. (2002) model are not satisfied, we use the Kormann and Meixner (2001) model. Figure 7 shows the footprint of the measurements for the MiTo station with the wind direction, which shows predominant upvalley (north, $340^{\circ}$ to $10^{\circ}$ ) and downvalley (south, $150^{\circ}$ to $200^{\circ}$ ) flow. 


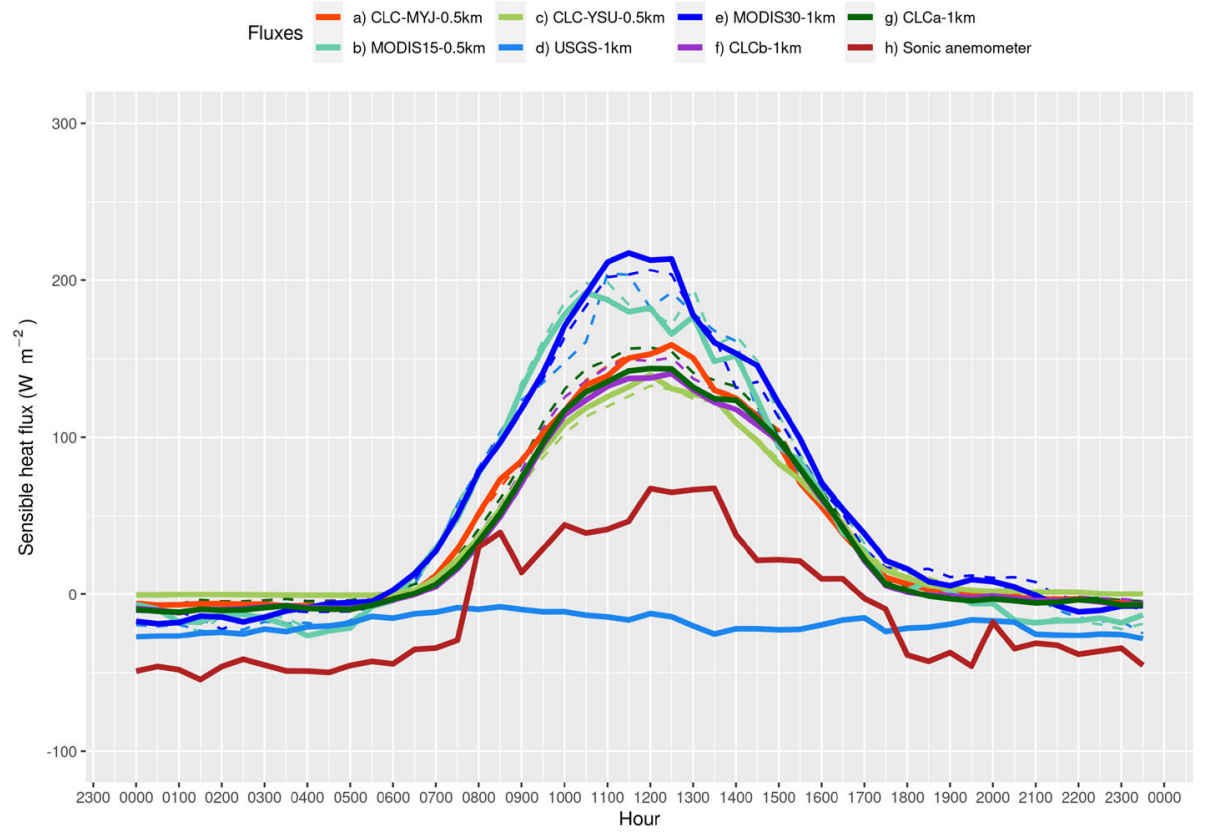

Fig. 6 Daily averaged sensible heat fluxes for the clear-sky days (28-30 August, 5-9 and 11 September) according to the observations (dark red) and the MODIS runs (aquamarine and blue) at $0.5-\mathrm{km}$ and $1-\mathrm{km}$ resolutions. Dark green, purple, orange and light green are the CLC set-ups, at $1 \mathrm{~km}$ and $0.5 \mathrm{~km}$, respectively; the light blue line represents the USGS-1 km results. Solid lines represent data the nearest grid point to the station location, while dashed lines represent the best nearest-neighbour grid point

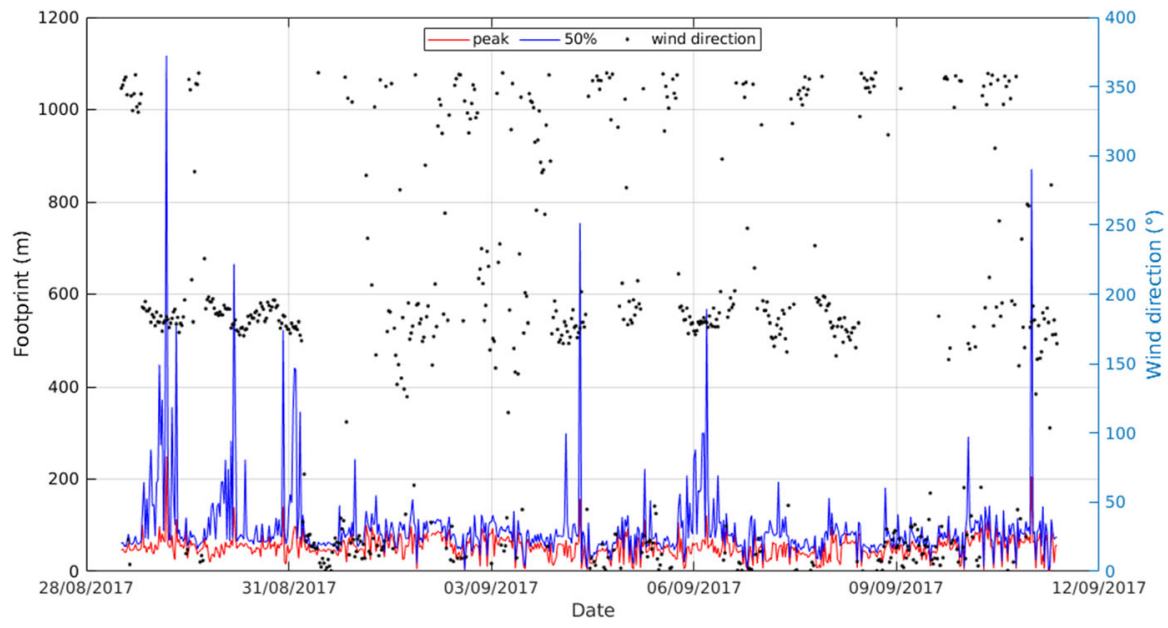

Fig. 7 Footprint calculations for the MiTo micrometeorological station showing the source peak measured fluxes (red), and the distance providing $50 \%$ of the measured fluxes (blue). The right $y$-axis reports the wind direction (black dots) to help identify the position of the flux sources. Dates on the $x$-axis correspond to midnight 
Figure 7 shows that, especially during the selected days, the peak of the flux source was within $150 \mathrm{~m}$ of the instrument, an area completely within the glacier foreland, while the $50 \%$ footprint is between $200 \mathrm{~m}$ to $400 \mathrm{~m}$, with peaks of more than $600 \mathrm{~m}$. Those peaks have a southerly direction, and occur during the night, which explains the low (approximately $-50 \mathrm{~W} \mathrm{~m}^{-2}$ ) night-time sensible heat fluxes measured; note that the footprint model locates the source partly on the glacier and partly on the foreland. This is consistent with the measurements showing the night-time fluxes more negative than in the simulations. The PBL parametrization calculates the sensible heat flux at the surface, and only the YSU parametrization considers the heat advection (in the case of an unstable boundary layer). In conclusion, the measured sensible heat flux is influenced by conditions over both the foreland, where the station was installed, and the glacier. The $0.5-\mathrm{km}$ set-up is able to detect the night-time conditions, with a downvalley circulation, but the low values of the sensible heat flux during daytime could not be explained by the simulations. There may have been a thin layer of cold air during the daytime responsible for the $50 \mathrm{~W} \mathrm{~m}^{2}$ to $60 \mathrm{~W} \mathrm{~m}^{2}$ observed daily fluxes. This stable and cold layer was consumed by the heating beneath bare ground, but consisently contributed to lowering the expected sensible heat flux. Furthermore, the position of the lowest model level at $4.5 \mathrm{~m}$ a.g.l. may not be low enough to resolve the thin layer of cold air and consequently, the model estimated higher sensible heat fluxes during daytime as regards the observations. Considering the footprint area, a concurrent effect is probably the slope shadowing on border zones; however, the valley orientation and the sun zenith angle produce a constant insolation of the valley floor.

\subsection{Comparison Between Simulations}

Here, the simulations are investigated to determine which change among land use, resolution, topography, and PBL parametrization has the greater impact on a selection of boundarylayer and soil variables, including the sensible heat flux, latent heat flux, ground heat flux, soil moisture (at the first level under the surface), mixing-layer height, 2-m temperature, $10-\mathrm{m}$ wind speed, skin temperature, and the difference between the 2-m temperature and skin temperature. The comparison is made by calculating the differences between the output fields, and later, a Student significance $t$-test was performed on each grid point with 14 degrees of freedom (the simulations were 14 days long). Whereas if only the clear-sky days were considered, the number of degrees of freedom decreased to nine (see Sect. 3.2.3). The significance level used is $90 \%$ ( $p_{\text {value }}<0.1$ ).

\subsubsection{Land Use}

The first three simulations of Table 4 (USGS-1 km, MODIS30-1 km and CLCa- $1 \mathrm{~km}$ ) allow comparison of the impact of different land use where we use the CLCa-1 km simulation as a reference and calculate differences with the MODIS30-1 km and USGS- $1 \mathrm{~km}$ simulations, and assessed using a Student $t$-test. Other parameters, such as the grid spacing, topography, and PBL parametrization, are fixed at $1 \mathrm{~km}$, GMTED2010 and MYJ parametrization, respectively.

The land-use datasets (Fig. 4) mainly differ in glacial areas (Forni and Adamello glaciers), built-up areas (Bormio), and the distribution of bare ground and forests. As can be seen in Fig. 4, in the USGS dataset, the glaciers are wider than in the MODIS30 and CLC datasets, and Bormio village is located correctly for the CLC land use, while its area is too large and is incorrectly located by the MODIS30 the village is not represented in the USGS dataset. 
Consequently, the fields of ground heat flux (maximum and minimum), sensible and latent heat fluxes (maximum), and soil moisture mainly differ in these areas, while the fields of 2-m temperature, mixing-layer height, and 10-m wind speed are not significantly different in the whole domain.

The installation of the MiTo station was over bare ground near the glacier boundary, where the new and finer resolution of the CLC dataset describes well the real land-use category, while the USGS land use positions the station on the Forni Glacier surface. The misplaced land-use category leads to a flattening of the daily evolution of the sensible heat flux in the USGS-1 km simulation, while the MODIS30-1 km and CLCa- $1 \mathrm{~km}$ simulations compute the typical daily evolution of the sensible heat flux (Fig. 6).

The comparison of different land use in the high-resolution simulations is done with MODIS15-0.5 km and CLC-MYJ-0.5 km set-ups. The two land-use datasets, MODIS15 and CLC, differ mostly along the slopes where MODIS15 localizes grassland while CLC reports bare soil (Fig. 4). The main differences between simulations are found in the ground, latent and surface heat fluxes (Fig. 8). In the MODIS15 land-use dataset, the grassland category has a lower value of thermal inertia and higher value of soil moisture availability than the bare-ground category in the CLC dataset. Consequently, the MODIS15-0.5 km simulation computes lower ground heat fluxes than the CLC-MYJ-0.5 km simulation (Fig. 8a, b). Moreover, soil moisture is always higher during MODIS15-0.5 km run than the CLC-MYJ-0.5 km run, and it also influences the latent heat flux computed by the MODIS15-0.5 km simulation with higher values with respect to the CLC-MYJ- $0.5 \mathrm{~km}$ simulation in the aforementioned areas (Fig. 8c). At lower altitudes where the land-use categories range between wooded areas, pastures, and croplands, the latent heat flux computed by the MODIS15-0.5 km simulation is lower due to different values in soil moisture availability, thermal inertia and heat capacity.

The WRF model calculates the sensible heat flux using the differences between temperature at the lowest model level and the skin temperature. The differences in the sensisble heat flux (minimum) from the MODIS15-0.5 km run and the CLC-MYJ-0.5 km run (Fig. 8d) depend on the gradients in the temperature as they were computed by the surface-layer parametrization. At night, the MODIS15-0.5 km simulation produces lower values of the sensible heat flux with respect to the CLC-MYJ-0.5 km simulation in middle-mountain areas, where the differences in simulated temperature gradient are maxima.

Focusing on the MiTo station position, where the MODIS15 and CLC land uses are different, the corresponding parameters show major differences in thermal inertia $\left(+1695.3 \mathrm{~J} \mathrm{~m}^{-2} \mathrm{~K}^{-1} \mathrm{~s}^{-1 / 2}\right)$, soil moisture availability (about $\left.+13 \%\right)$, and surface heat capacity (about $+8.8 \times 10^{5} \mathrm{~J} \mathrm{~m}^{-3} \mathrm{~K}^{-1}$ ), and is reflected in the energy-flux computation. Figure 9 shows the average clear-sky day evolution of ground, sensible, and latent heat fluxes. In moving from grasslands (MODIS15) to bare ground (CLC), a series of changes are identified: the albedo is increased and consequently the net radiation decreased; the soil moisture availability is decreased, leading to a lowering of the magnitude of the latent heat flux; the thermal inertia is increased and consequently the value of ground heat flux is increased; while the response of the sensible heat flux is more complex and related not much to the variation of temperature, but more to the decreased roughness length $\left(z_{0}\right)$ and wind speed.

\subsubsection{Topography and Resolution}

We compare simulations for different topography using the CLCa-1 km run with the default topography (GMTED2010) and the CLCb-1 km run using updated topography (NASA SRTM). In both cases, the topography is more detailed than the grid step. The results show that the change in topography alone is quite irrelevant. 

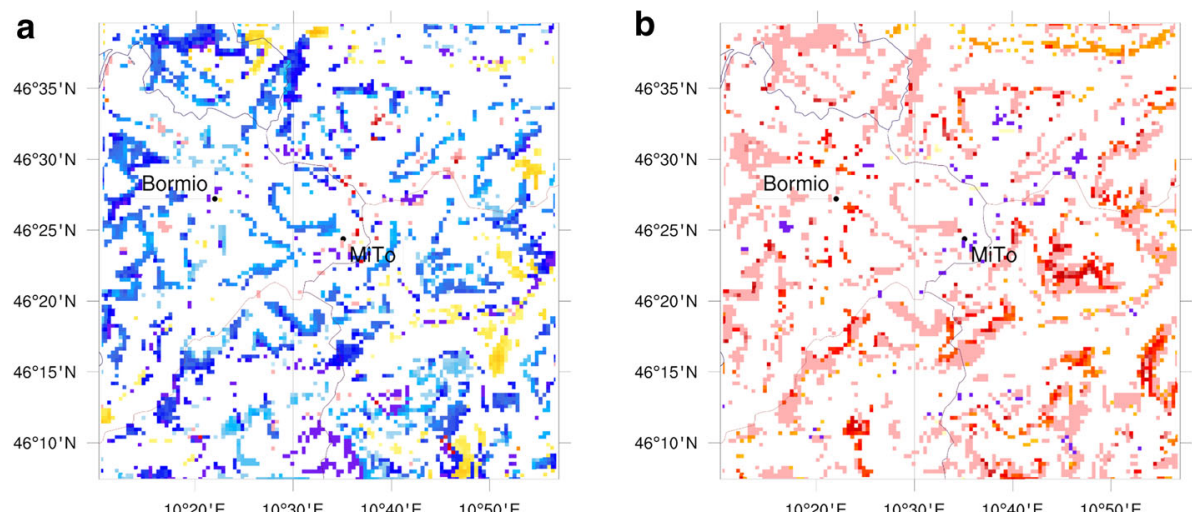

Ground heat flux differences $\left(\mathrm{W} \mathrm{m}^{-2}\right)$

$\begin{array}{lllllllllll}-50 & -40 & -30 & -20 & -10 & 0 & 10 & 20 & 30 & 40 & 50\end{array}$
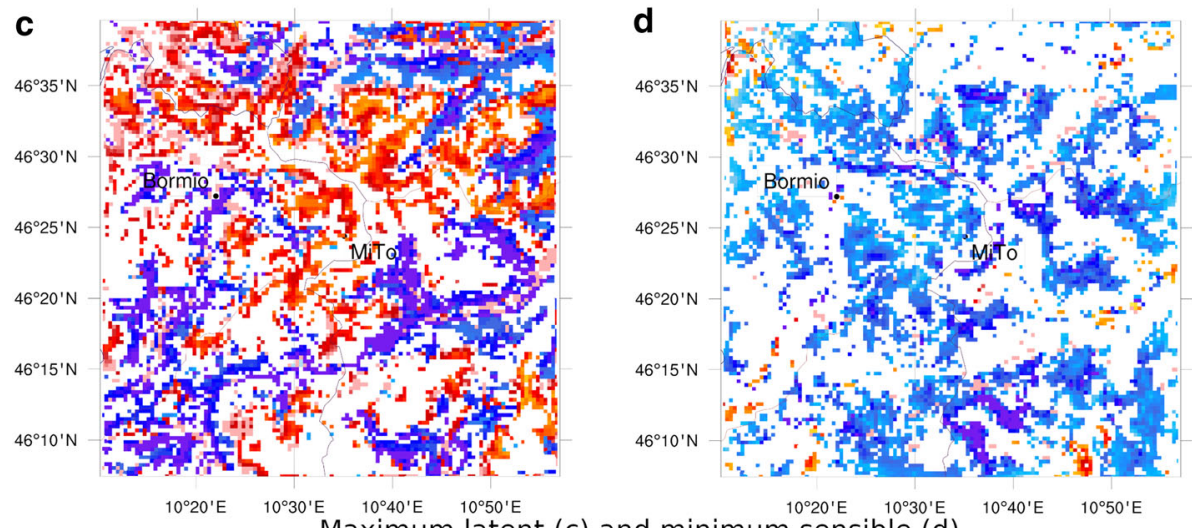

Maximum latent $(c)$ and minimum sensible $(d)$

heat flux differences $\left(\mathrm{W} \mathrm{m}^{-2}\right)$

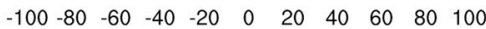

Fig. 8 Flux differences between the MODIS15-0.5 km and CLC-MYJ-0.5 km set-ups. Differences in maximum (a) and minimum (b) ground heat flux, c differences in maximum latent heat flux and differences in minimum sensible heat flux

We contrast the results at different resolutions for the CLCb-1 km and CLC-MYJ0.5-km runs, and compare with observations. Generally, they have similar performances (Tables 7, 8, 9) even if the number of stations is limited. Moreover, the outputs of the simulations that differ in grid spacing only (CLCb- $1 \mathrm{~km}$ and CLC-MYJ-0.5 km) can be qualitatively compared. In this case, the $0.5-\mathrm{km}$ resolution resolves local phemomena not seen in the simulation using a 1-km resolution. In particular, the vertical time profile of wind speed over the MiTo station (only the CLC-MYJ-0.5 km run is shown in Fig. 5) reveals that the 1-km grid-spacing simulation is not able to catch correctly the night-day flow reversal in narrow valleys (such as the Forni Glacier Valley), but produces a weak downvalley flow between 2230 and 0530 UTC. On the contrary, the CLC-MYJ-0.5 km run correctly computes the typical daytime and night-time mountain breezes. 


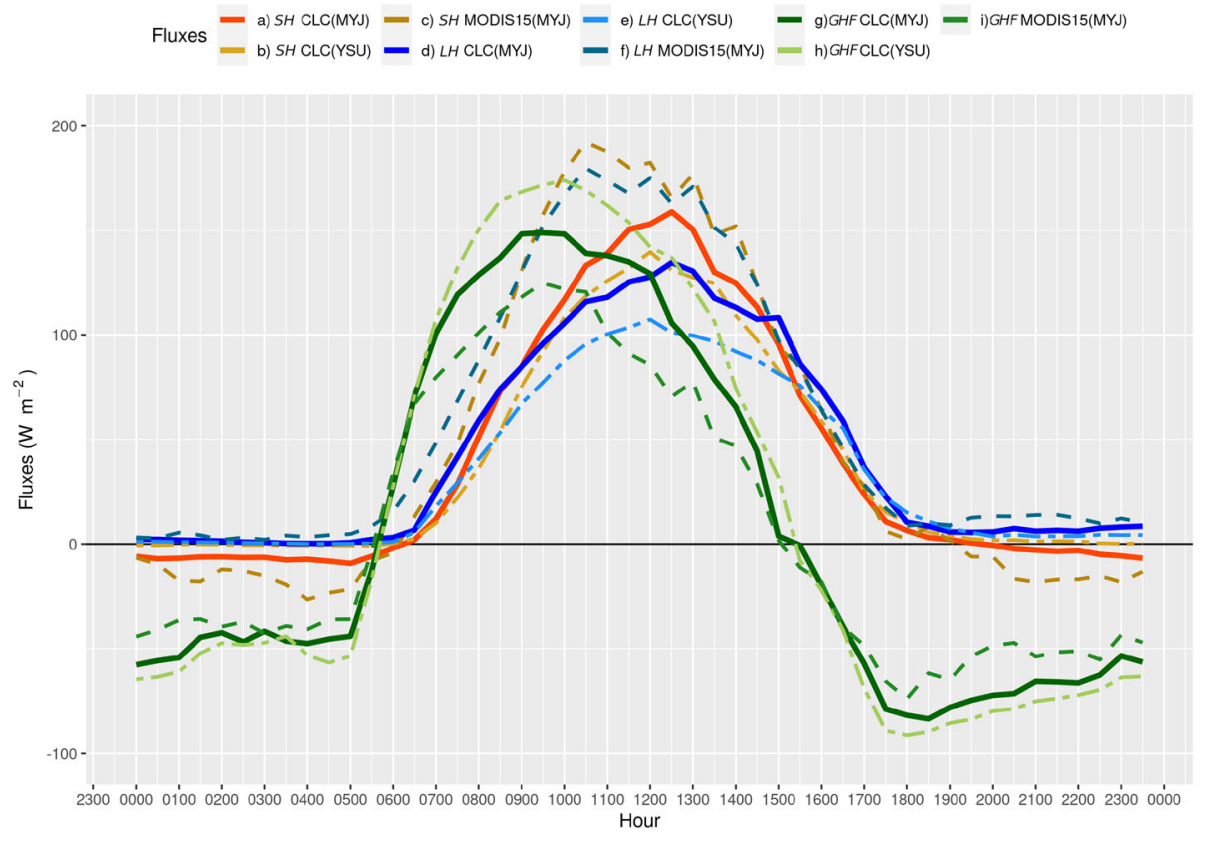

Fig. 9 Fluxes computed by the CLC-MYJ-0.5 km (continuous lines), CLC-YSU-0.5 km (two dash lines) and MODIS15-0.5 km (dashed lines) set-ups, including the sensible heat flux ( $\mathrm{SH}$, orange and similar colours), latent heat flux (LH, blue and similar colours), and ground heat flux (GHF, green and similar colours)

\subsubsection{Planetary-Boundary-Layer Parametrization}

Two different PBL parametrizations are considered in terms of $0.5-\mathrm{km}$ set-up to investigate whether high-resolution simulations are sensitive to them. The MYJ parametrization is applied in all other simulations, and it is considered the reference, while the YSU parametrization is used only in the last simulation (CLC-YSU-0.5 km). Several authors have compared the performance of local parametrizations (such as MYJ) and non-local parametrizations (such as YSU) in the evolution of the PBL over different localities, with each presenting advantages and disadvantages (a review is available in Cohen et al. 2015). The used PBL parametrizations allow different surface-layer parametrizations, where the MYJ parametrization is coupled with the Eta similarity parametrization, while the YSU parametrization is coupled with the Revised MM5 parametrization and the subgrid orography drag was activated. The land surface is parametrized in both cases by applying the Unified Noah parametrization. In conclusion, the surface fluxes are computed in the two cases by the coupled parametrizations Eta Similarity with Unified Noah and Revised MM5 with Unified Noah.

The main differences in outputs are relative to the maximum ground heat flux, minimum sensible heat flux, mixing-layer height, and wind gust at $10 \mathrm{~m}$ (Fig. 10). The YSU parametrization computes higher values of ground heat flux in the medium-mountain areas over the slopes and inside the valleys. The nocturnal sensible heat flux is significantly higher in the YSU simulation in almost the entire domain (Fig. 10b) and also at the MiTo station (Figs. 6 and 9). In this complex area, the YSU parametrization produces a sensible heat flux near zero, while the MYJ parametrization identifies (even if not completely) the negative night-time value of sensible heat flux, showing a greater temperature difference $\left(T_{2}-T_{\text {skin }}\right)$. The differences can 
be ascribed to the different parametrization of the stable nocturnal boundary layer. In fact, the YSU parametrization is a first-order non-local parametrization, but it parametrizes the stable nocturnal boundary layer in a local way, while the MYJ parametrization uses a local parametrization of the boundary layer and in several cases gives a better performance during stable conditions than some non-local parametrizations (Shin and Hong 2011; Draxl et al. 2012).

The difference in sensible heat flux arises from a lower 2-m temperature simulated by the MYJ run during the clear-sky days selected with respect to the YSU run. The statistics of Table 7 do not show such a difference, because they refer to the entire observation period. We expect the YSU run, as all non-local parametrizations, to represent deep PBL circulation more accurately than local parametrizations. In fact, especially at the mountain top, the YSU parametrization simulates a deeper PBL (Fig. 10c), but these features mainly apply during the daytime.

The wind gust (Fig. 10d) on clear-sky days shows negative differences in the range $-2 \mathrm{~m} \mathrm{~s}^{-1}$ to $-5 \mathrm{~m} \mathrm{~s}^{-1}$. The subgrid orography drag option reduces the wind speed, especially near slopes and high-peaks. The larger differences $\left(-5 \mathrm{~m} \mathrm{~s}^{-1}\right)$ are located on the Trentino side of the Ortles-Cevedale group and near the Adamello group, and is particularly significant in the area of Venosta Valley (north-north-east part of the domain); this is attributable to the complexity of this valley, with a wide valley floor characterized by many reliefs and roughnesses. The values in Table 8 show that the subgrid orography drag acted mainly at MiTo and Careser stations, which are both located in high mountain environments with complex topography. In these two cases, the value of RMSE is lowered between $1.9 \mathrm{~m} \mathrm{~s}^{-1}$ and $2.5 \mathrm{~m} \mathrm{~s}^{-1}$ for the wind speed and between $2.1 \mathrm{~m} \mathrm{~s}^{-1}$ and $2.6 \mathrm{~m} \mathrm{~s}^{-1}$ for the wind gust.

Figure 9 shows the daily evolution of fluxes according to the YSU and MYJ simulations at the MiTo station position. Here, the YSU run computes lower daily sensible and latent heat fluxes and higher ground heat fluxes with respect to the MYJ run, with maximum differences of $-19 \mathrm{~W} \mathrm{~m}^{-2},-27 \mathrm{~W} \mathrm{~m}^{-2}$, and $25 \mathrm{~W} \mathrm{~m}^{-2}$, respectively. During the night, the differences in fluxes are appreciable only in sensible heat fluxes that are lower in the MYJ run. As mentioned above, the PBL parametrizations differ for the local (MYJ) and non-local (YSU) treatment of turbulence, while the surface parametrizations (Eta similarity and Revised MM5 parametrizations) compute the friction velocities and the exchange coefficients that enable the calculation of surface heat and moisture fluxes by the land-surface models (Unified Noah in both case). In this complex area, the surface parametrizations are responsible for diurnal variation in flux values.

\section{Conclusions}

We compared seven WRF model set-ups with different land use (MODIS30, MODIS15, USGS, and CLC), static topography fields (GMTED2010, NASA SRTM) and PBL parametrizations (MYJ, YSU) at two different grid spacings $(0.5 \mathrm{~km}, 1 \mathrm{~km})$ to assess model sensitivity to these in complex mountainous terrain, and which of those is the most critical. In the simulations, the CLC dataset was implemented using its 44 categories, as suggested by Pineda et al. (2004). Furthermore, the WRF model was tested by comparing simulated data with measurements carried out at five meteorological stations in the period 28 August to 11 September 2017.

Our results answer the main four hypotheses expressed in the introduction: 


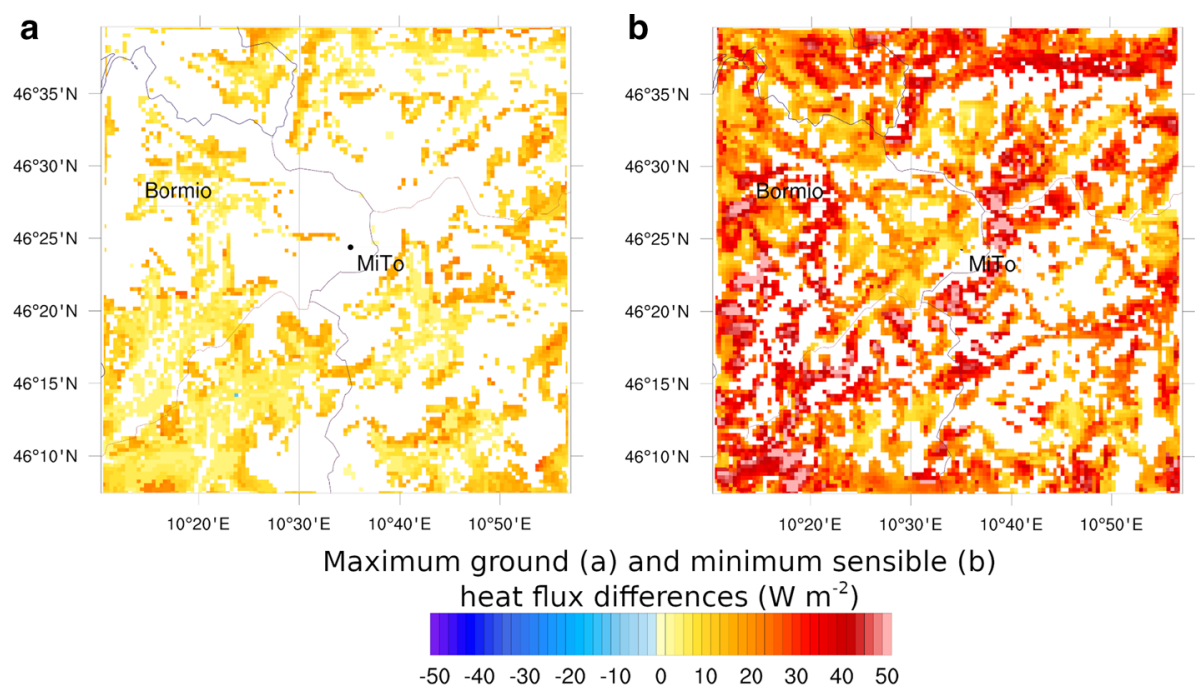

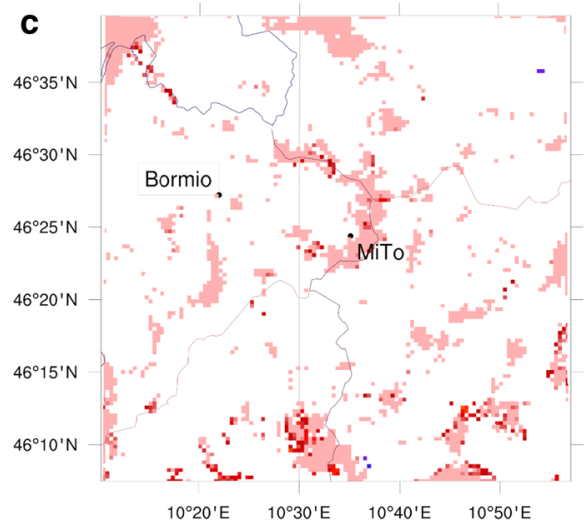

Mixing-layer-height differences ( $\mathrm{m}$ )

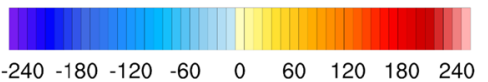

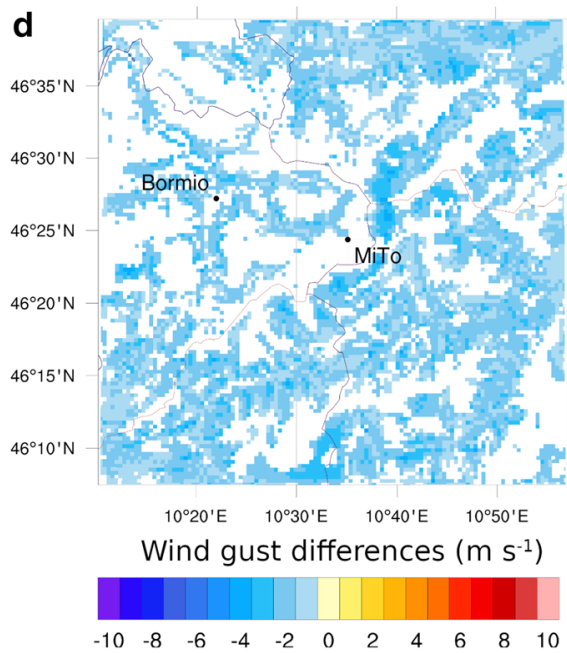

Fig. 10 Differences in the results of the CLC-YSU-0.5 km and CLC-MYJ-0.5 km simulations. a Differences in maximum ground heat flux, $\mathbf{b}$ differences in minimum sensible heat flux, $\mathbf{c}$ differences in maximum mixinglayer height, and $\mathbf{d}$ differences in wind gust

- A more detailed land-use dataset significantly improves the description of the simulated area. The CLC land-use data are much more realistic in comparison with the default dataset, and bring the full potentiality of this dataset with the complete set of parameters, previously calculated by Pineda et al. (2004). The application of CLC categories influenced the energy fluxes (Fig. 8) and their daily evolution (Figs. 6 and 9).

- The NASA SRTM topography is more similar to the actual topography than the GMTED2010 topography, differing by 50-100 m; however, this improvement without a higher model spatial resolution (reached with a finer grid spacing) did not produce a significant advantage. 
- The finer grid spacing $(0.5 \mathrm{~km})$ allows simulations to resolve valleys (about $3 \mathrm{~km})$, and correctly reproduces the diurnal mountain breeze inside the inspected Forni Valley.

- With regard to the PBL parametrization used, a non-local interaction generally lowered (focusing on the glacier foreland) the sensible and latent heat fluxes, thereby correctly considering the interaction with the glacier, but consistently increased the ground heat flux. This effect is attributable to the complex interaction between the surface-layer, boundary-layer, and land-surface parametrizations. Moreover, the mixing-layer height is in general increased by the YSU parametrization.

In conclusion, the most effective change is related to the land-use description, which could be consistently improved if the complete set of the land-use table parameters were evaluated for the entire CLC dataset.

Supplementary Information The online version contains supplementary material available at https://doi. org/10.1007/s10546-021-00617-1.

Acknowledgements The authors thank the Stelvio National Park for allowing the installation of the MiTo weather station, the Regional Agency for Environment Protection, the Weather Service of Trento Province, and the Weather Service of Bolzano Province for supplying weather data. The AWS1 Forni station has been developed by UNIMI, is hosted in the Stelvio Park, and is presently managed by UNIMI DESP with the financial support of Sanpellegrino SpA (Levissima). The acquired data are not only used for scientific research by UNIMI staff, but also shared with the WMO (World Meteorological Organization) in the framework of international programs (i.e. SPICE and CRYONET). The authors wish to personally thank Davide Bertoni for the assistance in building and preparing the MiTo station for the field campaign, Massimilano Manfrin for the experience and support with the WRF model, and Roberto Sergio Azzoni for valuable help in the field campaign set-up. A special thanks to the anonymous reviewers for their useful comments and suggestions, which considerably helped the authors improve the manuscript. The ECMWF data were provided by the MARS archive under the authorization of the Italian Air Force.

Funding Open access funding provided by Università degli Studi di Torino within the CRUI-CARE Agreement.

Open Access This article is licensed under a Creative Commons Attribution 4.0 International License, which permits use, sharing, adaptation, distribution and reproduction in any medium or format, as long as you give appropriate credit to the original author(s) and the source, provide a link to the Creative Commons licence, and indicate if changes were made. The images or other third party material in this article are included in the article's Creative Commons licence, unless indicated otherwise in a credit line to the material. If material is not included in the article's Creative Commons licence and your intended use is not permitted by statutory regulation or exceeds the permitted use, you will need to obtain permission directly from the copyright holder. To view a copy of this licence, visit http://creativecommons.org/licenses/by/4.0/.

\section{References}

Anderson J, Hardy E, Roach J, Witmer R (1976) A land use and land cover classification system for use with remote sensor data. U.S. Geological Survey, Geological survey professional paper 964

Balanzino A, Trini Castelli S (2018) Numerical experiments with RAMS model in highly complex terrain. Environ Fluid Mech 18:357-381. https://doi.org/10.1007/s10652-017-9553-9

Balzarini A, Angelini F, Ferrero L, Moscatelli M, Perrone MG, Pirovano G, Riva GM, Sangiorgi G, Toppetti AM, Gobbi GP, Bolzacchini E (2014) Sensitivity analysis of PBL schemes by comparing WRF model and experimental data. Geosci Model Dev Discuss 7:6133-6171. https://doi.org/10.5194/gmdd-7-61332014

Bollati I, Pellegrini M, Reynard E, Pelfini M (2017) Water driven processes and landforms evolution rates in mountain geomorphosites: examples from Swiss Alps. CATENA 158:321-339. https://doi.org/10.1016/ j.catena.2017.07.013

Büttner G, Soukup T, Kosztra B (2014) CLC2012 addendum to CLC2006 technical guidelines. European Environmental Agency, Tech rep 
Carlson BZ, Georges D, Rabatel A, Randin C, Renaurd J, Delestrade A, Zimmermann N, Choler P, Thuiller W (2014) Accounting for tree shift, glacier retreat and primary succession in mountain plant distribution models. Divers Distrib 20(12):137-1391

Carrivick JL, Heckmann T, Tumer A, Fischer M (2018) An assessment of landform composition and functioning with the first proglacial suystems dataset of the central european alps. Geomorphology 321:117-128

Cassardo C, Sacchetti D, Morselli GM, Anfossi D, Brusasca G, Longhetto A (1995) A study of the assessment of air temperature, and sensible-and latent-heat fluxes from sonic-anemometer observations. Il Nuovo Cimento C 18(4):419-440

Chou MD, Suarez MJ (1999) A solar radiation parameterization for atmospheric studies. NASA, Tech Memo 10460640

Cohen A, Cavallo S, Coniglio MC, Brooks HE (2015) A review of Planetary Boundary Layer Parameterization schemes and their sensitivity in simulating Southeastern U.S. cold season severe weather environments. Weather Forecast 30:591-612. https://doi.org/10.1175/WAF-D-14-00105.1

D’Agata C, Diolaiuti G, Maragno D, Smiraglia C, Pelfini M (2020) Climate change effects on landscape and environment in glacierized Alpine areas: retreating glaciers and enlarging forelands in the Bernina group (Italy) in the period 1954-2007. Geol Ecol Landsc 4(1):71-86

Danielson JJ, Gesch DB (2011) Global multi-resolution terrain elevation data 2010 (GMTED2010). U.S. Department of the Interior, U.S. Geological Survey, Open-File Report 2011-1073

De Meij A, Vinuesa J (2014) Impact of SRTM and Corine Land Cover data on meteorological parameters using WRF. Atmos Res 143:351-370. https://doi.org/10.1016/j.atmosres.2014.03.004

Doyle J, Epifanio C, Persson A, Reinecke P, Zängl G (2013) Mesoscale modelling over complex terrain: numerical and predictability perspectives. In: Mountain weather research and forecasting: recent progress and current challenges. Springer, Netherlands, pp 531-589. https://doi.org/10.1007/978-94-007-40983_9

Draxl C, Hahmann AN, Peña A, Giebel G (2012) Evaluating winds and vertical wind shear from Weather Research and Forecasting model forecasts using seven planetary boundary layer schemes. Wind Energy. https://doi.org/10.1002/we.-1555

Ferrero E, Alessandrini S, Vandenberghe F (2018) Assessment of planetary-boundary-layer schemes in the Weather Research and Forecasting model within and above an urban canopy layer. Boundary-Layer Meteorol 168:289-319. https://doi.org/10.1007/s10546-018-0349-3

Francese RG, Bondesan A, Giorgi M, Baroni C, Salvatore MC, Picotti S, Nicolis F (2015) Geophysical imaging of the WWI archeological site of Linke peak (Forni Glacier, Italian Central Alps). In: Near Surface Geoscience 2015-21st European Meeting of Environmental and Engineering Geophysics

Franzetti A, Pittino F, Gandolfi I, Azzoni R, Diolaiuti G, Smiraglia C, Pelfini M, Compostella C, Turchetti B, Buzzini P, Ambrosini R (2020) Early ecological succession patterns of bacterial, fungal and plant communities along a chronosequence in a recently deglaciated area of Italian Alps. FEMS Microbiol Ecol. https://doi.org/10.1093/femsec/fiaa165

Garavaglia V, Diolaiuti G, Smiraglia C, Pasquale V, Pelfini M (2012) Evaluating tourist perception of environmental changes as a contribution to managing natural resources in glacierized areas: a case study of the Forni Glacier (Stelvio National Park, Italian Alps). Environ Manag 50:1125-1138

Gerber F, Besic N, Sharma V, Mott R, Daniels M, Gabella M, Berne A, Germann U, Lehning M (2018) Spatial variability of snow precipitation and accumulation in COSMO-WRF simulations and radar estimations over complex terrain. Cryosphere. https://doi.org/10.5194/tc-2018-50

Giovannini L, Zardi D, de Franceschi M, Chen F (2014) Numerical simulations of boundary-layer processes and urban-induced alterations in an alpine valley. Int J Climatol 34:1111-1131. https://doi.org/10.1002/ joc. 3750

GLIMS, NSIDC (2018) Global land ice measurements from space glacier database. Compiled and made available by the international GLIMS community and the National Snow and Ice Data Center, Boulder CO, U.S.A. https://doi.org/10.7265/N5V98602

Gobbi M, Fontaneto D, De Bernardi F (2006) Influence of climate changes on animal communities in space and time. The case of spider assemblages along an alpine glacier foreland. Glob Change Biol 12(10):19851992

Goger B, Rotach MW, Gohm A, Stiperski I, Fuhrer O (2016) Current challenges for numerical weather prediction in complex terrain: topography representation and parameterizations. In: 2016 international conference on High Performance Computing \& Simulation (HPCS), IEEE. IEEE, Innsbruck, Austria. https://doi.org/10.1109/HPCSim.2016.7568428

Golzio A, Crespi A, Bollati I, Senese A, Diolaiuti G, Pelfini M, Maugeri M (2018) High-resolution monthly precipitation fields (1913-2015) over a complex mountain area centred on the Forni Valley (Central Italian Alps). Adv Meteorol. https://doi.org/10.1155/2018/9123814 
Golzio A, Bollati IM, Ferrarese S (2019) An assessment of coordinate rotation methods in sonic anemometer measurements of turbulent fluxes over complex mountainous terrain. Atmosphere 10(6):324. https://doi. org/10.3390/atmos10060324

Golzio A, Bollati IM, Luciani M, Pelfini M, Ferrarese S (2020) Weather simulation of extreme precipitation events inducing slope instability processes over mountain landscapes. Appl Sci 12(10):4243. https://doi. org/10.3390/app10124243

Gómez-Navarro J, Raible C, Dierer S (2015) Sensitivity of the WRF model to PBL parametrizations and nesting techniques: evaluation of surface wind over complex terrain. Geosci Model Dev Discuss 8:5437-5479. https://doi.org/10.5194/gmdd-8-5437-2015

Grell GA, Freitas S (2013) A scale and aerosol aware stochastic convective parameterization for weather and air quality modelling. Atmos Chem Phys Discuss 13:23,845-23,893. https://doi.org/10.5194/acpd-1323845-2013

Hong SY, Lim JOJ (2006) The WRF single-moment 6-class microphysics sheme (WSM6). J Korean Meteorol Soc 42(2):129-151

Hong SY, Noh Y, Dudhia J (2006) A new vertical diffusion package with an explicit treatment of entrainment processes. Mon Weather Rev 134:2318-2341. https://doi.org/10.1175/MWR3199.1

IPCC (2014) Climate change 2014, impact, adaptation and vulnerability, IPCC, Chap 13. Europe

Janjic ZI (1994) The step-mountain eta coordinate model: further developments of the convection, viscous sublayer, and turbulance closure schemes. Mon Weather Rev 122:927-945

Janjic ZI (2002) Nonsingular implementation of the Mellor-Yamada Level 2.5 Scheme in the NCEP Meso model. NCEP, Tech Rep 437

Jiménez PA, Dudhia J (2012) Improving the representation of resolved and unresolved topographic effects on surface wind in the WRF model. J Appl Meteorol Climatol 51:300-316. https://doi.org/10.1175/JAMCD-11-084.1

Jiménez PA, Dudhia J, González-Rouco JF, Navarro J, Montávez JP, García-Bustamante E (2012) A revised scheme for the WRF surface layer formulation. J Appl Meteorol Climatol 140:898-918. https://doi.org/ 10.1175/MWR-D-11-00056

Jiménez-Esteve B (2015) Land use influence in WRF model. A high resolution mesoscale modeling over Oriental Pyrenees. Master's thesis, Facultat de Física, Universitat de Barcelona

Jiménez-Esteve B, Udina M, Soler M, Pepin N, Mirò J (2018) Land use and topography influence in a complex terrain area: a high resolution mesoscale modelling study over the Eastern Pyrenees using the WRF model. Atmos Res 202:49-62. https://doi.org/10.1016/j.atmosres.2017.11.012

Kealy JC, Efstathiou GA, Breare RJ (2019) The onset of resolved boundary-layer turbulence at grey-zone resolutions. Boundary-Layer Meteorol 171:31-52. https://doi.org/10.1007/s10546-018-0420-0

Klemp JB, Dudhia J, Hassiotis AD (2008) An upper gravity-wave absorbing layer for NWP applications. Mon Weather Rev 136:3987-4004. https://doi.org/10.1175/2008MWR2596.1

Kljun N, Rotach M, Schmid H (2002) A three-dimensional backward Lagrangian footprint model for a wide range of boundary layer stratification. Boundary-Layer Meteorol 103:205-226

Kormann R, Meixner F (2001) An analytical footprint model for non-neutral stratification. Boundary-Layer Meteorol 99:207-224

LeMone MA, Chen F, Alfieri JG, Tewari M, Geerts B, Miao Q, Grossman RL, Coulter RL (2006) Influence of land cover and soil moisture on the horizontal distribution of sensible and latent heat fluxes in southeast kansas during IHOP2002 and CASES-97. J Hydrometeorol 8:68-87. https://doi.org/10.1175/JHM554.1

Masseroli A, Leonelli G, Bollati I, Trombino L, Pelfini M (2016) The influence of geomorphological processes on the treetree position in upper Valtellina (Central Italian Alps). Geogr Fis Din Quat 39(2):171-182

McMillen R (1988) An eddy correlation technique with extended applicability to non-simple terrain. BoundaryLayer Meteorol 43:231-245. https://doi.org/10.1007/BF00128405

Mlawer EJ, Taubman SJ, Brown PD, Iacono MJ, Clough SA (1997) Radiative transfer for inhomogeneous atmospheres: RRTM, a validated correlated-k model for the longwave. J Geophys Res 102(D14):16,66316,682

NASA-JPL (2013) NASA Shuttle Radar Topography Mission Global 3 arc second [data set]. NASA EOSDIS Land Processes DAAC, Tech rep, https://doi.org/10.5067/MEaSUREs/SRTM/SRTMGL3.003

Pelfini M, Gobbi M (2005) Enhancement of the ecological value of Forni Glacier as a possible new geomorphosite: new data from arthropods communities. Geogr Fis Din Quat 28:211-217

Pelfini M, Brandolini P, Carton A, Piccazzo M (2009) Geo-turist and geomorphological risk/impact. In: Geomorphosites, assessment, mapping and management. Pfeil Verlag, München. ISBN 978-3-89937094-2

Pelfini M, Leonelli G, Trombino L, Zerboni A, Bollati IM, Merlini A, Smiraglia C, Diolaiuti G (2014) New data on glacier fluctuations during the climatic transition at similar to 4000 cal. year BP from a buried log 
in the Forni Glacier forefield (Italian Alps). Rendiconti Lincei-Scienze Fisiche e Naturali 25(4):427-437. https://doi.org/10.1007/s12210-014-0346-5

Pineda N, Jorba O, Jorge J, Baldasano JM (2004) Using NOAA AVHRR and SPOT VGT data to estimate surface parameters: application to a mesoscale meteorological model. Int J Remote Sens 25(1):129-143. https://doi.org/10.1080/0143116031000115201

Pröbstl-Haider U, Dabrowska K, Haider W (2016) Risk perception and preferences of mountain tourists in light of glacial retreat and permafrost degradation in the Austrian Alps. J Outdoor Recreat Tourism 13:66-78

Raup B, Racoviteanu A, Khalsa S, Helm C, Armstrong R, Arnaud Y (2007) The GLIMS geospatial glacier database: a new tool for studying glacier change. Glob Planet Change 56:101-110. https://doi.org/10. 1016/j.gloplacha.2006.07.018

Richiardone R, Giampiccolo R, Ferrarese S, Manfrin M (2008) Detection of flow distortion and systematic errors in sonic anemometry using the planar fit method. Boundary-Layer Meteorol 128(2):277-302. https://doi.org/10.1007/s10546-008-9283-0

Richiardone R, Manfrin M, Ferrarese S, Francone C, Fernicola V, Gavioso R, Mortarini L (2012) Influence of the sonic anemometer temperature calibration on turbulent heat-flux measurements. Boundary-Layer Meteorol 142(3):425-442. https://doi.org/10.1007/s10546-011-9688-z

Roşu I, Ferrarese S, Radinschi I, Ciocan V, Cazacu MM (2019) Evaluation of different WRF parametrizations over the region of Iaşi with remote sensing techniques. Atmosphere 10:559. https://doi.org/10.3390/ atmos 10090559

Schicker I, Arias DA, Seibert P (2016) Influence of updated land-use datasets on WRF simulations for two Austrian regions. Meteorol Atmos Phys 128:279-301. https://doi.org/10.1007/s00703-015-0416-y

Senese A, Maugeri M, Meraldi E, Verza G, Azzoni R, Compostella C, Diolaiuti G (2018) Estimating the snow water equivalent on a glacierized high elevation site (Forni Glacier, Italy). Cryosphere 12(4):1293-1306

Shin HH, Hong SY (2011) Intercomparison of planetary boundary-layer parametrizations in the WRF model for a single day from CASES-99. Boundary-Layer Meteorol 139(2):261-281. https://doi.org/10.1007/ s10546-010-9583-z

Skamarock W, Klemp JB, Dudhia J, Gill DO, Barker DM, Duda M, Huang XY, Wang W, Powers JG (2008) A description of the advanced research WRF version 3. Mesoscale and Microscale Meteorological Division NCAR, Boulder, Colorado, USA, Tech rep

Smagorinsky J (1963) General circulation experiments with the primitive equations: I. The basic esperiment. Mon Weather Rev 91(3):99-164. https://doi.org/10.1175/1520-0493(1963)091<0099:GCEWTP>2.3. $\mathrm{CO} ; 2$

Smiraglia C, Diolaiuti G, Azzoni R (2016) The new Italian glacier inventory. Italian Research Council EvK2CNR

Stiperski I, Rotach MW (2016) On the measurements of turbulance over complex mountainous terrain. Boundary-Layer Meteorol 159:97-121. https://doi.org/10.1007/s10546-015-0103-z

Stull RB (1988) An introduction to boundary-layer meteorology. Kluwer Academic Publishers, Dordrecht

Sun X, Holmes HA, Osibanjo OO, Sun Y, Ivey CE (2017) Evaluation of surface fluxes in the WRF model: case study for farmland in rolling terrain. Atmosphere 8:197. https://doi.org/10.3390/atmos8100197

Tewari M, Chen F, Wang W, Dudhia J, LeMone M, Mitchell K, Ek M, Gayno G, Wegiel J, Cuenca R (2004) Implementation and verification of the unified NOAH land surface model in the WRF model. In: 20th conference on weather analysis and forecasting/16th conference on numerical weather prediction

Tunner CB, Thurtell GW (1969) Anemoclinometer measurements of Reynolds stress and heat transport in the atmospheric surface layer. ECOM, United States Army Electronics Command, Research and Development 66-G22-F

Tyagi B, Magliulo V, Finardi S, Gasbarra D, Carlucci P, Toscano P, Zaldei A, Riccio A, Calori G, D’Allura A, Gioli B (2018) Performance analysis of Planetary Boundary Layer parameterisation schemes in WRF modeling set up over Southern Italy. Atmosphere 9:272. https://doi.org/10.3390/atmos9070272

Wilczak J, Oncley S, Stage S (2001) Sonic anemometer tilt correction algorithms. Boundary-Layer Meteorol 99:127-150. https://doi.org/10.1023/A:1018966204465

Wyngaard JC (2004) Toward numerical modelling in the "terra incognita”. J Atmos Sci 61:1816-1826. https:// doi.org/10.1175/1520-0469(2004)061<1816:TNMITT>2.0.CO;2

Zanoner T, Carton A, Seppi R, Carturan L, Baroni C, Salvatore MC, Zumiani M (2017) Little Ice Age mapping as a tool for identifying hazard in the paraglacial environment: the case study of Trentino (Eastern Italian Alps). Geomorphology 295:551-562

Publisher's Note Springer Nature remains neutral with regard to jurisdictional claims in published maps and institutional affiliations. 